\title{
Strength Prediction of Adhesive Joints after Cyclic Moisture Conditioning Using a Cohesive Zone Model
}

\author{
A. Mubashar ${ }^{a}$, I. A. Ashcroft ${ }^{a, *}$, G. W. Critchlow ${ }^{b}$, A. D. Crocombe \\ ${ }^{a}$ Wolfson School of Mechanical and Manufacturing Engineering, Loughborough University, \\ Loughborough, Leicestershire LE11 3TU, UK \\ ${ }^{b}$ Department of Materials, Loughborough University, Loughborough, Leicestershire LE11 3TU, UK \\ ${ }^{\circ}$ Division of Mechanical, Medical, and Aerospace Engineering, University of Surrey, Guildford GU2 7HX,

\begin{abstract}
This paper presents a methodology to predict the strength of adhesive joints under variable moisture conditions. The moisture uptake in adhesive joints was determined using a history dependent moisture prediction methodology where diffusion coefficients were based on experimental cyclic moisture uptake of bulk adhesive samples. The predicted moisture concentrations and moisture diffusion history were used in a structural analysis with a cohesive zone model to predict damage and failure of the joints. A moisture concentration and moisture history dependent bilinear cohesive zone law was used. The methodology was used to determine the damage and failure in aluminium alloy - epoxy adhesive single lap joints, conditioned at $50^{\circ} \mathrm{C}$ and good predictions of failure load were observed. The damage in the adhesive joints decreased the load carrying capacity before reaching the failure load and a non linear relationship between the load and displacement was observed. Changes in crack initiation and crack propagation were also observed between different types of joints. The presented methodology is generic and may be applied to different types of adhesive joint and adhesive.
\end{abstract}

Keywords: Adhesion, Finite element method, Strength Prediction, Cyclic moisture,

* Corresponding author. Tel: +44 1509 227535; fax: +44 1509223934

Email address: i.a.ashcroft@lboro.ac.uk(I.A.Ashcroft) 
Durability

\section{Introduction}

The use of adhesives in structural applications is increasing [1-3] owing to a number of advantages offered by adhesive joints over other methods of joining. These include low weight, high stiffness and good fatigue resistance. The stresses are usually distributed over a larger area in adhesive joints compared to mechanical fasteners and there is no heat affected zone, as is found in welded joints. On the other hand, environmental factors such as temperature and moisture are known to adversely affect the performance of adhesive joints $[1,4,5]$. A number of degradation models / mechanisms have been proposed, which attempt to explain the deleterious influence of water within adhesive joints [6-10].

Absorption of moisture in epoxy adhesives degrades the mechanical properties of the adhesive, which may contribute to reduction in joint strength. The effect of moisture absorption on the mechanical properties of a bulk epoxy adhesive was observed by ZanniDeffarges and Shanahan [11]. Moisture diffusion was carried out at $70^{\circ} \mathrm{C}$ under $100 \%$ relative humidity (RH). A $20 \%$ decrease in the elastic modulus of the bulk adhesive samples aged to saturation as compared to the unconditioned samples was observed. Loh et al [12] also observed a progressive decrease in the elastic modulus (E) and ultimate tensile stress $\left(\sigma_{\mathrm{ult}}\right)$ of bulk adhesive samples with increasing moisture concentration when subjected to $81.2 \%$, 95.8\% $\mathrm{RH}$ and immersed in water.

Recovery in strength of adhesives is observed after the absorbed moisture was dried. Lin and Chen [13] observed that tensile strength and the elastic modulus of a DGEBA/DDA epoxy polymer decreased by $29.5 \%$ and $29.1 \%$ respectively, after the moisture absorption. When the samples were dried, the strength and the elastic modulus recovered to at least $90 \%$ of the unconditioned values. Plasticisation of the adhesive was proposed as the main reason for the 
observed degradation in the mechanical properties of the adhesive. As plasticisation is considered potentially reversible [14], large recoveries in the elastic modulus and the tensile strength were observed after drying the sample, however, the elastic modulus and tensile strength did not return completely to the levels measured in the unconditioned state. This suggested that some irreversible mechanisms were also present. Moisture can affect adhesives in an irreversible manner via a number of potential mechanisms including; chemical degradation, chain scission and micro-cracking [14].

Cohesive zone models (CZM) have been used increasingly in recent years to simulate crack initiation, propagation and failure [15-19]. The cohesive zone method offers a number of advantages over other methods for the determination of damage and failure such as; no initial crack is required to model failure and a small number of parameters are needed to calibrate the model when compared to most continuum damage models. A methodology for the determination of cohesive zone model parameters and its application to different joint configurations has been successfully implemented by Crocombe and his co-workers [5, 2022]. The cohesive energy of the adhesive and substrate system was determined using a mixed mode flexure joint (MMF) in three point bend configuration. The failure loads of unconditioned and conditioned MMF specimens were used to determine the cohesive zone model parameters. These were then used to model the joint durability of single lap, double lap and L-joints. Good correlation was found in the predicted and experimental strengths of the joints.

In [23], a methodology for predicting the transient moisture distribution in adhesive joints under cyclic moisture conditions was introduced. In this paper, the methodology is used in combination with cohesive zone modelling to determine the progressive damage and failure in single lap joints subjected to cyclic environmental ageing. The cohesive zone model was calibrated using a combination of experimental and numerical methods. The calibrated model 
was used to predict the strength of single lap joints, conditioned for different time intervals at $50^{\circ} \mathrm{C}$ in water.

\section{Experimental Methods}

The structural adhesive FM73-M, available from Cytec Engineered Materials Ltd, New Jersey, USA was used in the manufacture of bulk adhesive samples and adhesive joints. FM73-M is a single part, heat setting, rubber toughened epoxy, which comes in film form and has a polyester knit carrier for support and handling. The manufacturer's recommended curing temperature of $\mathrm{FM} 73-\mathrm{M}$ is $120^{\circ} \mathrm{C}$.

To simulate the strength of adhesive joints under cyclic moisture conditions, the cyclic moisture diffusion and mechanical properties of the adhesive were determined. The moisture diffusion properties of the adhesive were determined by the gravimetric method and have been reported in [23]. The moisture dependant mechanical properties of the adhesive were determined by tensile testing bulk adhesive samples, which were cut from cured sheets of the bulk adhesive according to BS EN ISO 527-2:1996 [24]. The tensile test samples were conditioned at $50^{\circ} \mathrm{C}$, immersed in water, for absorption, and desorption cycles. At preselected time intervals, samples were withdrawn from the conditioning environment and tensile testing was carried out using an Instron 3366 dual column testing machine, with a displacement rate of $1 \mathrm{~mm} / \mathrm{min}$. At least three tensile samples were tested at each selected time interval. The strain was measured using a strain gauge based contact extensometer. The specimens were wrapped with cling film to minimise any changes in moisture concentration during the transportation to the test machine and tensile testing.

Single lap joints were used to determine changes in joint strength after moisture diffusion. The single lap joint adherends were manufactured from unclad aluminium alloy 2024 in T3 heat treated (A12024 T3) and non heat treated (A12024 O) state to study the effect of 
adherend stiffness on joint strength. The joints were prepared according to BS ISO 4587:2003 [25] and their configuration and geometry are shown in Figure 1. The adherends were cut from $3.2 \mathrm{~mm}$ thick Al2024 T3 and O sheets and their surfaces were prepared by degreasing followed by ACDC anodising. ACDC anodising is an environmental friendly pre-treatment process, which is free from the hexavalent chromium found in the aerospace industry standard chromic acid anodising (CAA).

In ACDC anodising, the adherends act as anodes in a DC phase and alternatively as anodes and cathodes in an AC phase. The adherends are suspended in an aqueous solution of $2.5 \%$ phosphoric plus $2.5 \%$ sulphuric acid and an alternating current (AC) applied at a voltage of $15 \mathrm{~V}$ for 2 minutes at $35^{\circ} \mathrm{C}$. This process is followed by the application of direct current (DC) with a voltage of $20 \mathrm{~V}$ for 10 minutes at $35^{\circ} \mathrm{C}$. The adherends are then rinsed with water and dried in air. The ACDC anodising process provides a high energy, porous oxide surface on the adherends, which is ideal for adhesive bonding, with a dense, corrosion resistant layer adjacent to the aluminium. Further details of the ACDC pretreatment may be found in [26].

The ACDC pretreatment was followed by the application of BR127 corrosion inhibiting primer, which was air dried at room temperature for 30 minutes and then cured for one hour at $120^{\circ} \mathrm{C}$. During curing, the adhesive and the adherends were held together by clips and bondline thickness was maintained by the carrier in the adhesive film. The adhesive was cured at $120^{\circ} \mathrm{C}$ for one hour and the final bondline thickness was $0.12 \pm 0.02 \mathrm{~mm}$. Fillets were formed at the ends of the overlap due to out-flow of the adhesive and the average size of the fillets was $1 \mathrm{~mm}$.

A set of three unconditioned joints was tensile tested at room temperature using a Hounsfield H20K-W tensometer to obtain the initial failure strength. The rest of the joints were conditioned in water at $50^{\circ} \mathrm{C}$. Sets of six joints were removed from the conditioning 
environment at predefined intervals of $7,14,28,56$ and 182 days. Three joints from the extracted set were immediately tensile tested and the remaining three joints were placed in an oven for drying at $50^{\circ} \mathrm{C}$. The drying time for the joints was the same as the absorption time for each joint. After drying, the joints were brought to room temperature in a desiccator and tensile testing was carried out. The joints dried after conditioning will hereafter be referred to as "dried joints", however, it should be noted that some residual moisture may be present in the joints.

Plastic deformation was not observed in the Al2024 T3 adherends during tensile testing of the adhesive joints whilst significant plastic deformation was seen in the Al2024 O adherends. Thus, tensile testing of $\mathrm{Al} 2024 \mathrm{O}$ specimens was carried out to determine the elasto-plastic material properties, which were used later in the finite element models. Three specimens of A12024 O were tensile tested using an Instron 3366 dual column testing machine and the strain was measured using a contact type extensometer.

\section{Experimental Results}

Stress in bulk adhesive specimens as a function of strain at different moisture conditions is plotted in Figure 2. The plots are the average from testing three specimens at each moisture condition where stresses had a standard deviation of $\pm 2.6 \mathrm{MPa}$. The moisture content in each bulk adhesive specimen is given as the ratio of moisture content at any time, $M_{t}$, measured by gravimetric means, to the saturated moisture content, $M_{\infty}$, i.e. $M_{t} / M_{\infty}$. During the absorption cycle, an increase in strain to failure, over unconditioned specimens, was observed for all moisture concentrations. The increased strain to failure may be due to plasticisation of the adhesive by the absorbed moisture. In dried bulk adhesive samples, the strain to failure 
decreased to a value less than the unconditioned samples, which indicates a combination of reversible and irreversible effects on the absorption of moisture by the adhesive.

A representative stress-strain curve obtained from tensile testing A12024 O tensile specimens is given in Figure 3 and the mechanical properties of the Al2024 T3 and O adherends are given in Table 1. The change in failure load of the single lap joints with conditioning time is shown in Figure 4. The Al2024 T3 joints showed a decrease in the failure load with increasing conditioning time. When A12024 T3 joints were dried after conditioning, they recovered between $98 \%$ and $100 \%$ of the original strength. The recovered percentage of the original strength was similar for all moisture absorption time intervals. It can be seen in Figure 4 that the strength of unconditioned A12024 O joints is significantly less than that of Al2024 T3 joints. This can be attributed to the plastic deformation of the A12024 O adherends during tensile testing, which occurred because of the lower yield stress of Al2024 O (75.8 MPa) compared to Al2024 T3 (345 MPa). This resulted in higher strains in adhesive fillets causing higher peel stresses and resulting in lower joint strength. The Al2024 O joints also showed a more rapid decrease in strength than the Al2024 T3 joints in the initial conditioning period of 14 days. However, a strength increase was then observed after tensile testing for 28 days of conditioning. After moisture absorption for 56 days, the strength of the joint recovered to about $86 \%$ of its original strength and remained at a similar value after conditioning of 182 days. The Al2024 O joints were also tested after drying and the strength recovered to $88 \%$ or more of the unconditioned joint strength.

It has been proposed that moisture affects the strength of a joint through a change in the adhesive properties and potentially also by attacking the adhesive-adherend interface [1]. However, utilising advanced preparation methods, such as the ACDC anodisation process used in the present research, the effect of water at the interface can be minimised, resulting in 
durable structures. The two main types of failure observed in the joints were cohesive failure and apparent interfacial failure. Cohesive failure in the adhesive layer was observed in the A12024 T3 and O single lap joints tested in the unconditioned state. In the Al2024 T3 conditioned joints, cohesive failure predominated in joints tested after 7, 14, 28 and 56 days, whereas, a mixed failure was observed in the joints conditioned for 182 days. However, patches of apparent interfacial failure were present to some degree on most of the failure surfaces. A similar pattern of cohesive or mixed failure was observed in the dried joints.

In Al2024 O joints, the failure surfaces showed increasing levels of apparent interfacial failure as the failure load of the joint decreased after 7 and 14 days of moisture absorption when the strength of the conditioned joints started to increase after 28 days of moisture absorption, the ratio of cohesive to interfacial failure followed a trend similar to joint strength. In A12024 O joints dried after conditioning, an increase in the apparent interfacial failure was observed in joints conditioned for 7 and 14 days and then dried. As the joint strength increased after 28 days of conditioning, increased cohesive failure was also observed. Similar behaviour was observed after 56 and 182 days of conditioning, where mostly cohesive failure was observed.

\section{Finite Element Modelling}

A cyclic moisture diffusion prediction methodology was presented in [23], which is able to predict moisture concentration in bonded joints over multiple cycles of absorption and desorption. The methodology was implemented using a user sub-routine in the commercially available finite element code Abaqus, Dassault Systemes, Providence, RI, USA. The moisture history of the adhesive was maintained by use of scalar internal state variables. In this paper, the cyclic moisture diffusion prediction methodology is coupled with cohesive zone model 
for the prediction of damage and failure in joints when subjected to variable environmental conditions.

The framework for strength prediction under cyclic moisture conditions is given in Figure 5. The moisture history dependence of mechanical properties was introduced in the model by using field variables. The moisture history and moisture process i.e. absorption or desorption are stored in state variables in the form of a spatially resolved field for the adhesive layer. The moisture history, normalised concentration and moisture process definitions required for the predictive strength model were obtained from a cyclic moisture diffusion analysis.

A built-in cohesive zone modelling capability is available in Abaqus, which was employed in this study to predict the failure load of single lap joints in both conditioned and unconditioned states. A bilinear constitutive cohesive zone law was selected for modelling the single lap joints as this has been successfully used to model failure in bonded joints in the literature [15, 20, 27-29] and provides a good compromise between computational cost and the number of elements required to represent the damage zone and failure [30]. The bilinear cohesive zone law is shown in Figure 6 in the form of a traction-separation response where $G_{c o h}$ is the cohesive energy, $K$ is the stiffness, $\sigma_{i}$ is the traction, $\sigma_{c}$ is the tripping traction, $\delta$ is displacement, $\delta_{c}$ is the critical displacement and $\delta_{f}$ is the final displacement. A stress criterion was used for damage initiation where the damage was assumed to initiate when the ratio of stress at any time increment to the maximum stress reached a value of one as given by Equation (1).

$$
\max \left(\frac{\left\langle\sigma_{n}\right\rangle}{\sigma_{n, \max }}, \frac{\sigma_{s}}{\sigma_{s, \max }}, \frac{\sigma_{t}}{\sigma_{t, \text { max }}}\right)=1
$$


where $\sigma_{n, \max }$ is the maximum stress in the normal direction, $\sigma_{s, \max }$ and $\sigma_{t, \max }$ are the maximum stresses in transverse shear directions. $\sigma_{n}, \sigma_{s}$ and $\sigma_{t}$ are the corresponding stresses at any time increment. " \langle\rangle " is a Macaulay bracket, showing that no damage occurs under pure compression.

The bilinear cohesive zone model may be completely defined by $G_{c o h}, K$, and $\sigma_{c}$. Turon et al [31] provided a relationship for determining the value of stiffness based on the properties of the surrounding material, which for an isotropic material is given by:

$$
K=\frac{\alpha E}{t}
$$

where $E$ is the elastic modulus, $t$ is the thickness of material surrounding the cohesive elements and $\alpha$ is a parameter whose value should be much larger than $1(\alpha>>1)$. A value of 50 or greater was recommended for $\alpha$ [31]. Based on Equation (2), the value of stiffness was calculated to be $8.3 \times 10^{5} \mathrm{~N} / \mathrm{mm}^{3}$, however, convergence difficulties were observed during modelling and a lower value of $1 \times 10^{5} \mathrm{~N} / \mathrm{mm}^{3}$ was used for the cohesive zone model. The moisture dependent fracture energy of adhesive FM73 was determined by Liljedahl et al [20] using a mixed mode flexure (MMF) specimen. MMF specimens were tested under dry, $80 \% \mathrm{RH}$ and $96 \% \mathrm{RH}$ conditions and the failure load was used to determine the fracture energies. The experimental fracture energy as a function of moisture content is given in Figure 7 [20]. This was used as the moisture dependent value of $G_{c o h}$ in the cohesive zone model.

A penalty based cohesive zone finite element approach, as suggested by Diehl [28, 32] was used to determine $\sigma_{c}$. A two dimensional single lap joint with Al2024 T3 adherends and FM73 adhesive was modelled. The adhesive was modelled using elastic continuum elements and a layer of cohesive elements was embedded in the mesh based on the experimental 
observations of crack growth. Two dimensional, continuum four node, plane strain elements were used for the adhesive and the adherends. The mesh, along with the boundary conditions and loading for the two dimensional model, is shown in Figure 8. The joint was loaded by prescribed displacement and the predicted failure load was calibrated to the experimental failure load to determine the value of $\sigma_{c}$. The force vs. displacement response of the calibrated single lap joint model is shown in Figure 9. The finalised parameters for the bilinear cohesive zone law are given in Table 2.

The moisture dependence in the CZM was introduced by using a moisture dependent $G_{c o h}$. The moisture concentration and moisture history, which were stored in the form of state variables in the hygroscopic model, were used as initial conditions in the CZM analysis. The $G_{c o h}$ was defined as:

$$
G_{c o h}\left(C_{t}, F V 1, F V 2\right)
$$

where $F V 1$ and $F V 2$ are field variables and $C_{t}$ is the normalised moisture content at any point in the adhesive layer. The field variables (FV1, FV2) were used to relate moisture dependent material properties to state variables containing moisture concentration and moisture history using an Abaqus USDFLD user subroutine. USDFLD allows the definition of field variables at a material point as a function of time or any available material point quantity [33]. The change in the cohesive zone law based on the moisture dependent cohesive energy is shown in Figure 10. The model incorporates mode I and mode II failure modes but it is assumed that fracture energy and the moisture effect do not change with mode mixity, which is consistent with previous work [22, 34]. 


\section{Strength Prediction of Single Lap Joints}

Single lap joints with $\mathrm{A} 12024 \mathrm{~T} 3$ and $\mathrm{O}$ adherends, conditioned in deionised water at $50^{\circ} \mathrm{C}$, were modelled using the proposed methodology. A three dimensional (3D) model of the single lap joint was used, owing to the moisture and structural boundary condition requirements. A quarter model, based on symmetry in the geometry and the loading was used. Continuum, eight node, linear elements with incompatible modes (C3D8I) were used for meshing the adhesive layer. The adherends were meshed using a combination of continuum and continuum shell elements, as shown in Figure 11. The continuum elements were the same type as those used in the adhesive layer, whilst the continuum shell elements were eight node, quadrilateral, reduced integration elements (SC8R).

A layer of the cohesive zone elements, of $0.005 \mathrm{~mm}$ thickness, was embedded between the continuum elements of the adhesive and the adherends on a crack path determined from experimental observations. A finite thickness was necessary as the analysis was carried out in two steps. In the first step, moisture diffusion analysis was carried out and the normalised moisture concentrations were determined. During moisture diffusion analysis, continuum, 8 node, linear heat transfer elements (DC3D8) were used for meshing. Moisture diffusion was modelled across the adhesive and CZM elements. Since the same mesh was used in second step to predict the damage and failure based on the CZM, elements of very small thickness were used in moisture diffusion analysis, which were later converted to cohesive zone elements for the structural analysis. The single lap joints were loaded by prescribed displacement. As previously described, a sequential mechanical analysis was carried out and the results of the diffusion analysis were used as initial conditions in the structural analysis. The experimental failure load of the single lap joints, as given in Figure 4, was used to validate the predicted strength. 
For the A12024 T3 joints, an elastic material definition was used for the adherends and moisture and moisture history dependent elastic properties were used for the adhesive (the effect of introducing plasticity in modelling the adhesive layer is discussed in a previous paper [35]). The prescribed load-displacement responses of the unconditioned and 182 days conditioned T3 joints are shown in Figure 12. It can be seen that the initial load-displacement curves for both unconditioned and 182 days conditioned T3 joints are linear. In unconditioned T3 joints, the load-displacement response becomes nonlinear after approximately $8.2 \mathrm{kN}$ of load as represented by the dashed lines in Figure 12. At this point, $20 \%$ of the overlap and $91.7 \%$ of the fillet area was damaged, as determined by the finite element model. In 182 days conditioned T3 joints, a nonlinear load-displacement response was observed when $15.5 \%$ of the overlap and $65.9 \%$ of the fillet area was damaged. This indicates that the load carrying capacity of the joints start to decrease with the onset of significant damage appearing in the adhesive layer and fillet, at loads lower than the failure load of the joint.

The predicted and experimental failure loads for the A12024 T3 joints are plotted in Figure 13. The predicted unconditioned failure load was approximately $5 \%$ higher than the experimental unconditioned failure load. For conditioned T3 joints, the predicted failure load is in good agreement with the experimental failure load for all the conditioning time intervals. When the T3 joints were dried after moisture conditioning, they regained most of their unconditioned strength and similar behaviour was observed in the predictive modelling. The predicted failure load under all dried conditions was higher than the experimental failure load and was within $7 \%$ of the experimental results. The difference between the failure load of the experimental and predicted unconditioned T3 joints may be attributed to the differences of meshing, element type and element formulation between the 2D and 3D models, since the cohesive zone model parameters for unconditioned joint were calibrated using a 2D model. 
The adherends of the $\mathrm{O}$ joints were modelled using an elasto-plastic material model and moisture history dependent elastic properties were used for the adhesive. A von-Mises yield surface with associated flow was used along with an isotropic hardening law. The cohesive zone model parameters used were the same as those used for the T3 joints. The predicted force vs. displacement response of the unconditioned $\mathrm{O}$ joints may be seen in Figure 14 where a nonlinear relationship between force and displacement was observed after load of 1.8 $\mathrm{kN}$. In this case, it can be attributed to the plastic deformation of the adherends as damage was not visible in the adhesive at this load in either the unconditioned or 182 days conditioned joints.

A comparison between the experimental and finite element predicted plastic deformation of the adherends of the unconditioned $\mathrm{O}$ joints after loading to is shown in Figure 15. A good correlation between the shape of the experimentally deformed adherends and the finite element model exists. The experimental and predicted failure loads of the $\mathrm{O}$ joints, conditioned for various time intervals, are shown in Figure 16. The failure load of the unconditioned $\mathrm{O}$ joint was under-predicted by approximately $9 \%$ by the model. The predicted failure loads at conditioning times of 7,14 and 28 days were higher than the average experimental failure loads and were within $11.5 \%$ of the average failure loads. The experimental strength of the $\mathrm{O}$ joints recovered somewhat after 56 and 182 days of moisture conditioning, however, the finite element model predicted a progressive decrease in the failure load under these conditions. The strength of the dried $\mathrm{O}$ joints was under predicted at all moisture conditions except for 7 days of moisture conditioning, however, the predicted strength was within $6 \%$ of the average experimental results. 


\section{Crack Initiation and Propagation}

Damage and crack development in the unconditioned T3 joints, as predicted by the finite element modelling, are shown in

Figure 17. The geometry of the single lap joint used to show contour plots is developed by cross sectioning the joint with two cutting planes shown in

Figure 17a. The contour plots show the damage, represented by a scalar damage variable SDEG, in the adhesive layer and it can be seen that most of the overlap region was damaged before rupture occurred. The crack initiated in the fillet region, labelled as $\mathrm{A}$ in

Figure $17 \mathrm{~b}$, and the major crack growth direction initially was towards the edges i.e in the $\mathrm{Z}$ direction; as shown in

Figure 17c. Once the crack reached the edges, it propagated towards the middle of the overlap, in the $\mathrm{X}$ direction as may be seen from

Figure 17e. Similar type of crack initiation was experimentally observed by Shenoy et al [36] while testing single lap joints manufactured using FM73-M adhesive and aluminium 7075-T6 adherends. Crack growth was observed in the middle of the joint and the developed crack was concave in shape. This agrees well with the finite element predicted crack growth shape as shown in 
Figure 17.

Crack initiation in the T3 joints conditioned for 182 days was in the fillet region, labelled as $\mathrm{B}$ in

Figure 18a, which was similar to the unconditioned joints. However, at the time of the crack initiation, the damage zone in the conditioned $\mathrm{T} 3$ joints was much smaller than in the unconditioned T3 joints. After crack initiation, the major crack growth occurred from region B towards edges, as given in

Figure 18b. However, in the unconditioned joints, cracks also initiated from the edges of the adherends, as shown in

Figure $18 \mathrm{c}$, the two sets of cracks eventually joining to form a cross width crack as shown in Figure 18d. The crack then progressed towards the middle of the overlap, in the X direction, however, in the conditioned joint the crack length is longest at the edges, whereas, it can be seen in

Figure 17e that in the unconditioned joints the crack length is always greater in the middle of the joint width. This is potentially significant if crack length is being measured experimentally by observation of the joint edges.

The crack propagation rate in the unconditioned and conditioned $\mathrm{T} 3$ joints may be compared by plotting the change in crack length with applied displacement. The crack lengths of the unconditioned and 182 days conditioned T3 joints, as a function of applied displacement, are plotted in Figure 19. After crack initiation, a region of stable crack growth exists for both unconditioned and 182 days conditioned T3 joints. The stable crack growth is followed by a period of rapid growth leading to failure. The stable crack growth in the unconditioned T3 joints occurred for a shorter duration than in the 182 days conditioned T3 joints. This may be 
attributed to the more ductile response of the adhesive after moisture absorption. Once a major portion of the adhesive layer was damaged, failure occurred virtually instantaneously in both unconditioned and conditioned T3 joints.

Crack initiation in the $\mathrm{O}$ joints occurred at the outer fillet edge in region $\mathrm{C}$, as can be seen in Figure 20a, which was different from the T3 joints where crack initiated in the middle of the fillet. This can be more clearly seen in Figure 21. After the crack initiation, major crack growth occurred towards the edges, i.e. in $\pm \mathrm{Z}$ directions, and once the crack reached the edges, the crack propagated towards the middle of the overlap in the $\mathrm{X}$ direction. The damage zone was smaller in the unconditioned $\mathrm{O}$ joints than the unconditioned $\mathrm{T} 3$ joints during crack propagation. The difference in crack initiation region between $\mathrm{O}$ and $\mathrm{T} 3$ joints may be because of the increased peel stresses in the $\mathrm{O}$ joints, resulting from the plastically induced adherend rotation. In the $\mathrm{O}$ joints conditioned for 182 days, the crack initiation location was similar to the 182 days conditioned T3 joints, as shown in

Figure 22. The crack propagated towards the middle of the overlap, in the $\mathrm{X}$ direction, after reaching the joint edges.

There are three regions of crack propagation after crack initiation in the unconditioned $\mathrm{O}$ joints, as may be seen in Figure 23. A relatively fast crack growth region is followed by a period of slow, more stable crack growth. This is then followed by another period of rapid crack growth, this time leading to failure of the joint. In the 182 days conditioned $\mathrm{O}$ joints similar behaviour is seen, however, the region of slow crack growth is smaller than in the unconditioned $\mathrm{O}$ joints. Comparison of Figure 19 and Figure 23 shows that the crack propagation was more gradual in the $\mathrm{O}$ joints than the $\mathrm{T} 3$ joints. 


\section{Summary and Conclusions}

A cohesive zone model was used to predict the damage and failure in single lap joints under cyclic moisture conditions. The first step in the prediction of joint strength is the prediction of moisture diffusion in the adhesive joint, which was carried out using a history dependent moisture prediction methodology. The history dependent moisture prediction methodology used diffusion coefficient obtained from cyclic moisture uptake of bulk adhesive samples. The diffusion prediction methodology was coupled with a structural analysis methodology where cohesive zone model was used to predict the damage and failure in single lap joints. Batches of unconditioned and conditioned T3 and $\mathrm{O}$ single lap joints were tensile tested to determine the effects of moisture diffusion on joint strength. The single lap joints were conditioned by immersing in deionised water at $50^{\circ} \mathrm{C}$ and dried after conditioning. A significant recovery in the joint strength was observed after drying.

The results of the finite element analysis show that the failure initiation region in an adhesive joint may change based on the strength of the adherends and the moisture distribution in the adhesive. The load carrying capacity of joints starts to decrease as damage appears in the joint. This occurs at a load lower than the failure load, thus, only using failure criteria to predict the strength of joints may over predict the failure loads. It was also observed that the crack growth before sudden failure, in a conditioned single lap joint, is more stable than in an unconditioned joint. The proposed variable moisture and strength prediction methodology can successfully predict the strength of adhesive joints under variable environmental conditions. 


\section{References}

[1] Minford JD. Handbook of Aluminum Bonding Technology and Data. New York: Marcel Dekker, Inc.; 1993.

[2] Grant LDR, Adams RD, da Silva LFM. Experimental and numerical analysis of single-lap joints for the automotive industry. International Journal of Adhesion and Adhesives. 2009;29:405-13.

[3] da Silva LFM, das Neves PJC, Adams RD, Spelt JK. Analytical models of adhesively bonded joints - Part I: Lieterature survey. Int J Adhesion and Adhesives. 2009;29:319-30.

[4] Hand HM, Arah CO, McNamara DK, Mecklenburg MF. Effects of environmental exposure on adhesively bonded joints. Int J Adhesion and Adhesives. 1991;11:15-23.

[5] Liljedahl CDM, Crocombe AD, Wahab MA, Ashcroft IA. Modelling the Environmental Degradation of the Interface in Adhesively Bonded Joints using a Cohesive Zone Approach. The Journal of Adhesion. 2006;82:1061-89.

[6] Bowditch MR. The durability of adhesive joints in the presence of water. Int J Adhesion and Adhesives. 1996;16:73-9.

[7] Apicella A, Nicolais L, Astarita G, Drioli E. Effect of thermal history on water sorption, elastic properties and the glass transition of epoxy resins. Polymer. 1979;20:1143-8.

[8] De'Nève B, Shanahan MER. Water absorption by an epoxy resin and its effect on the mechanical properties and infra-red spectra. Polymer. 1993;34:5099-105.

[9] Katya II, Richard AP, Affrossman S. Hygrothermal aging of rubber modified and mineral filled dicyandiamide cured DGEBA epoxy resin. III. Dielectric spectroscopy investigation. J Appl Polym Sci. 2002;84:1011-24.

[10] Liu J, Lai Z, Kristiansen H, Khoo C. Overview of conductive adhesive joining technology in electronics packaging applications. Proceedings of 3rd International Conference on Adhesive Joining and Coating Technology in Electronics Manufacturing: IEEE; 1998. p. 1-18.

[11] Zanni-Deffarges MP, Shahnahan MER. Diffusion of water into an epoxy adhesive: comparision between bulk behaviour and adhesive joints. Int J Adhesion and Adhesives. 1995; 15:137-42.

[12] Loh WK, Crocombe AD, Wahab MA, Ashcroft IA. Modelling anomalous moisture uptake, swelling and thermal characteristics of a rubber toughened epoxy adhesive. Int $\mathbf{J}$ Adhesion and Adhesives. 2005;25:1-12.

[13] Lin YC, Chen X. Moisture sorption-desorption-resorption characteristics and its effects on the mechanical behaviour of the epoxy system. Polymer. 2005;46:11994-2003.

[14] Shuangyan Xu, Dillard DA, Dillard JG. Environmental aging effects on the durability of electrically conductive adhesive joints. Int J Adhesion and Adhesives. 2003;23:235-50. 
[15] Zhang L, Wang J. A generalized cohesive zone model of the peel test for pressuresensitive adhesives. Int J Adhesion and Adhesives. 2009;29:217-24.

[16] Ural A, Krishnan VR, Papoulia KD. A cohesive zone model for fatigue crack growth allowing for crack retardation. Int J Solids Struct. 2009;46:2453-62.

[17] Zavattieri PD, Hector Jr LG, Bower AF. Cohesive zone simulations of crack growth along a rough interface between two elastic-plastic solids. Engineering Fracture Mechanics. 2008;75:4309-32.

[18] Freed Y, Banks-Sills L. A new cohesive zone model for mixed mode interface fracture in bimaterials. Engineering Fracture Mechanics. 2008;75:4583-93.

[19] Carlberger T, Stigh U. An explicit FE model of impact fracture in an adhesive joint. Engineering Fracture Mechanics. 2007;74:2247-62.

[20] Liljedahl CDM, Crocombe AD, Wahab MA, Ashcroft IA. Modelling the environmental degradation of adhesively bonded aluminium and composite joints using a CZM approach. Int J Adhesion and Adhesives. 2007;27:505-18.

[21] Liljedahl CDM, Crocombe AD, Wahab MA, Ashcroft IA. The effect of residual strains on the progressive damage modelling of environmentally degraded adhesive joints. $\mathbf{J}$ Adhesion Sci Technol. 2005;19:525-47.

[22] Crocombe AD, Hua Y, Loh WK, Wahab MA, Ashcroft IA. Predicting the residual strength for environmentally degraded adhesive lap joints. Int J Adhesion and Adhesives. 2006;26:325-36.

[23] Mubashar A, Ashcroft IA, Critchlow GW, Crocombe AD. Modelling cyclic moisture uptake in an epoxy adhesive. J Adhesion. 2009;85:711-35.

[24] BS EN ISO 527-2:1996 Plastics - Determination of tensile properties - Part 2: Test conditions for moulding and extrusion plastics. British Standards Institution.

[25] BS ISO 4587:2003 Adhesives - Determination of tensile lap-shear strength of rigid-torigid bonded assemblies. British Standards Institution.

[26] Critchlow GW, Ashcroft IA, Cartwright T, Bahrani D. Anodising aluminium alloy. United Kingdom2 421959 A, 2006.

[27] de Moura MFSF, Chousal JAG. Cohesive and continuum damage models applied to fracture characterization of bonded joints. Int J Mech Sci. 2006;48:493-503.

[28] Diehl T. On using a penalty-based cohesive-zone finite element approach, Part II: Inelastic peeling of an epoxy-bonded aluminum strip. International Journal of Adhesion and Adhesives. 2008;28:256-65.

[29] Fan C, Jar PYB, Cheng JJR. Cohesive zone with continuum damage properties for simulation of delamination development in fibre composites and failure of adhesive joints. Engineering Fracture Mechanics. 2008;75:3866-80. 
[30] Alfano G. On the influence of the shape of the interface law on the application of cohesive-zone models. Composites Science and Technology. 2006;66:723-30.

[31] Turon A, Davila CG, Camanho PP, Costa J. An engineering solution for mesh size effects in the simulation of delamination using cohesive zone models. Engineering Fracture Mechanics. 2007;74:1665-82.

[32] Diehl T. On using a penalty-based cohesive-zone finite element approach, Part I: Elastic solution benchmarks. International Journal of Adhesion and Adhesives. 2008;28:237-55.

[33] Abaqus User Subroutines Reference Manual. Dassault Systemes Simulia Corp. Providence, RI, USA; 2008.

[34] Loh WK, Crocombe AD, Abdel Wahab MM, Ashcroft IA, Environmental degradation of the interfacial fracture energy in an adhesively bonded joint, Engineering Fracture Mechanics, 2002; 69: 2113-2128.

[35] Mubashar A, Ashcroft IA, Critchlow GW, Crocombe AD, A method of predicting the stresses in adhesive joints after cyclic conditioninig, Journal of Adhesion, in press.

[36] Shenoy V, Ashcroft IA, Critchlow GW, Crocombe AD, Abdel Wahab MM. An investigation into the crack initiation and propagation behaviour of bonded single-lap joints using backface strain. Int J Adhesion and Adhesives. 2009;29:361-71.

[37] Kutz M. Handbook of Materials Selection. New York: John Wiley \& Sons, Inc.; 2002.

[38] Cardarelli F. Materials Handbook - A Concise Desktop Reference. 2nd ed. London: Springer-Verlag London Limited; 2008. 

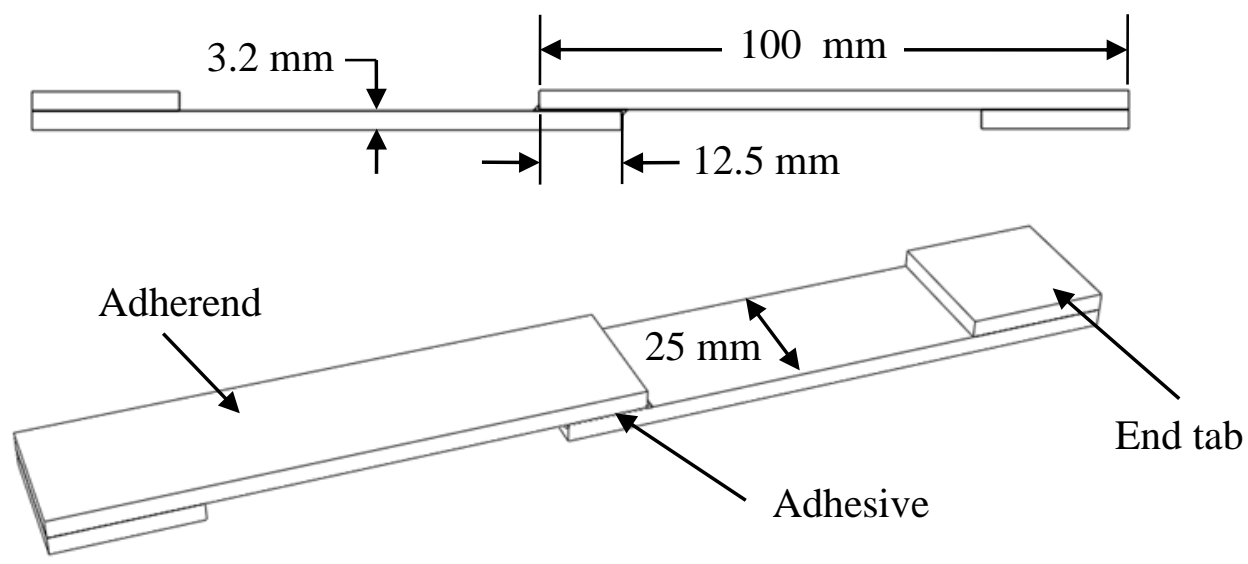

Figure 1: Single lap joint configuration and geometry.

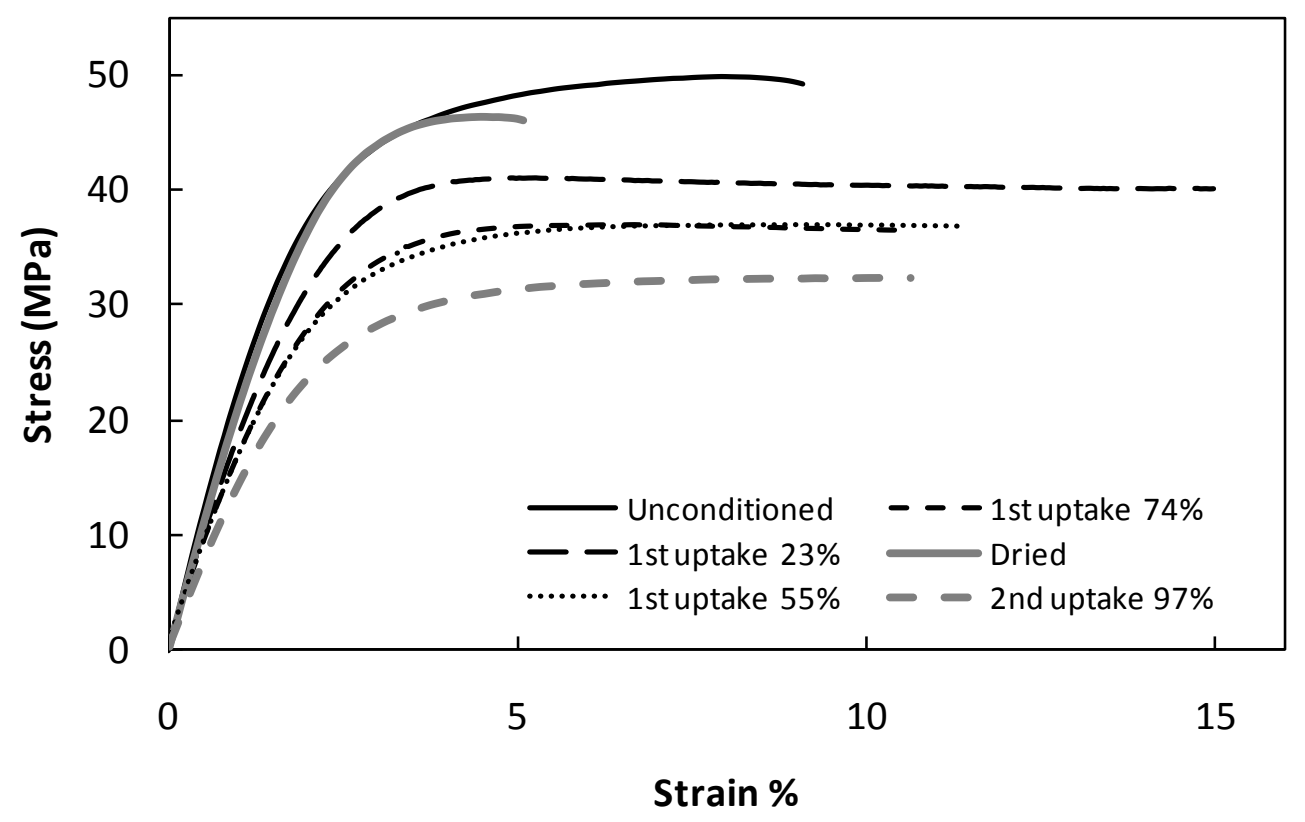

Figure 2: Moisture dependant stress vs. strain curves for the adhesive at different values of $M_{t} / M_{\infty}$. 


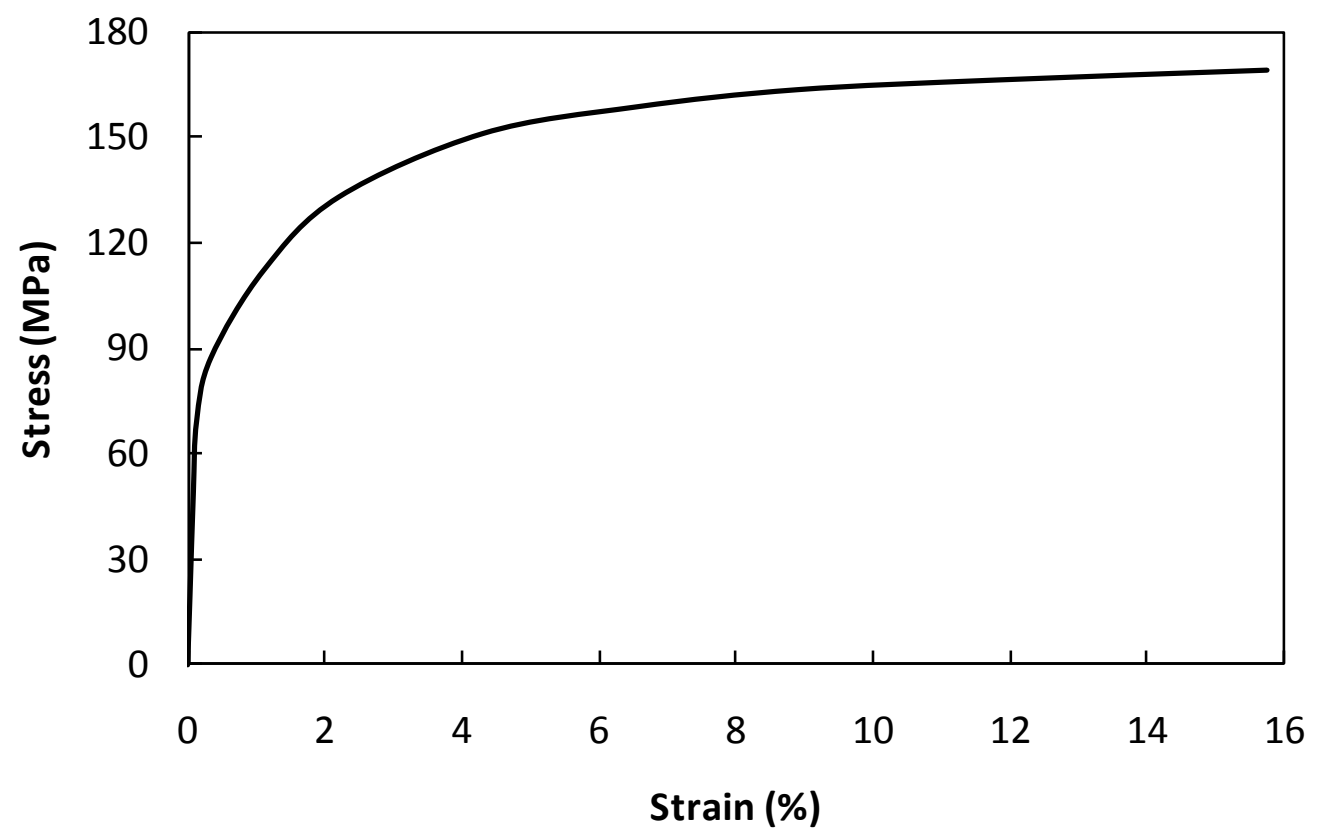

Figure 3: Tensile stress vs strain response of Al2024 O.

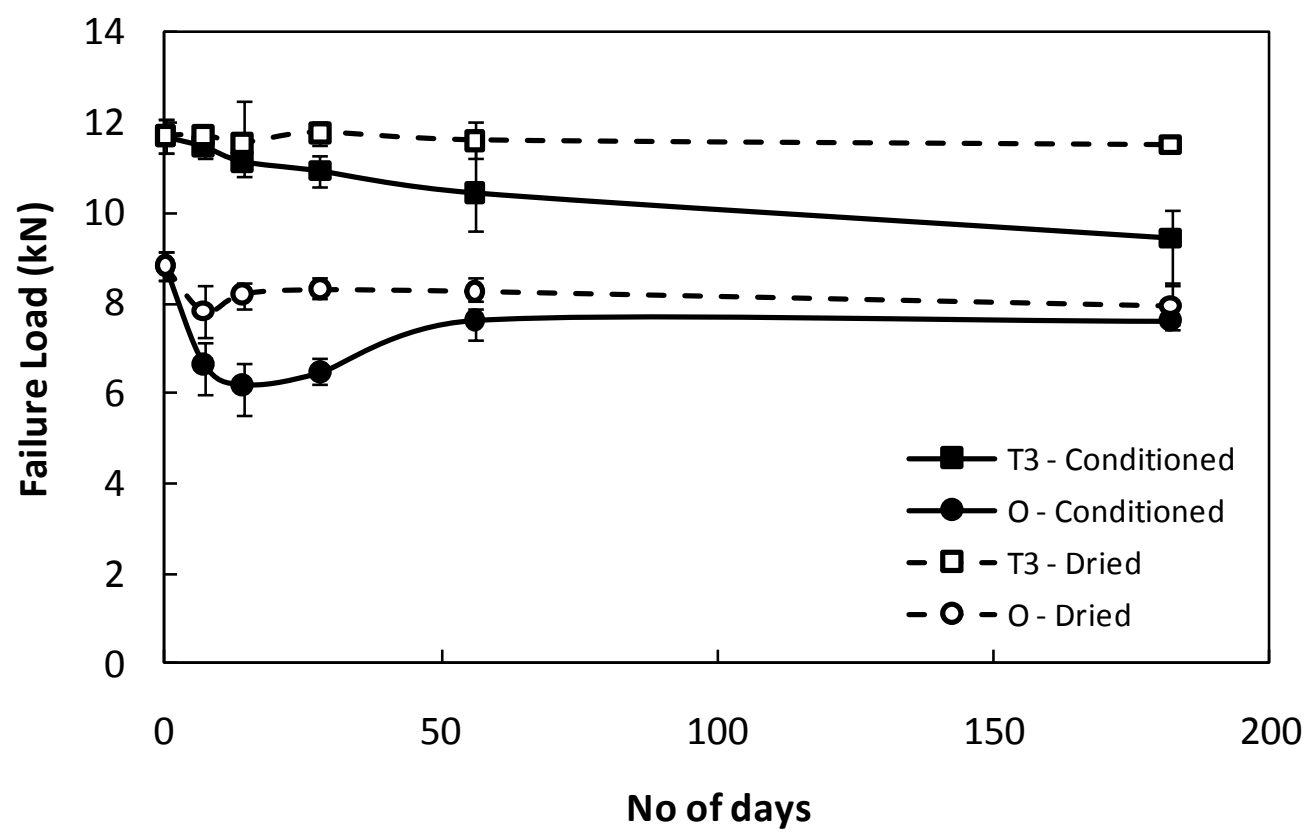

Figure 4: Failure load of single lap joints after conditioning at $50^{\circ} \mathrm{C}$, immersed in water and subsequent drying in air at $50^{\circ} \mathrm{C}$. 


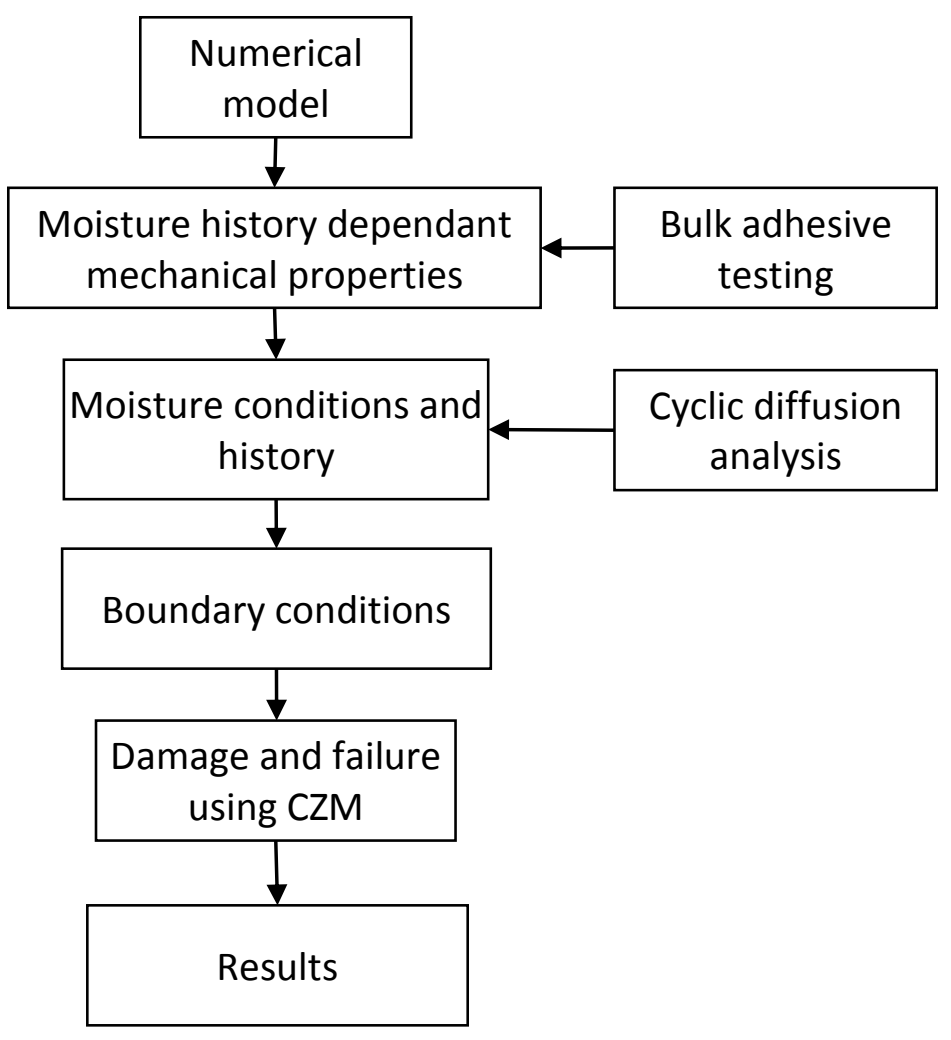

Figure 5: Overall methodology for the strength prediction of cyclic conditioned structures.

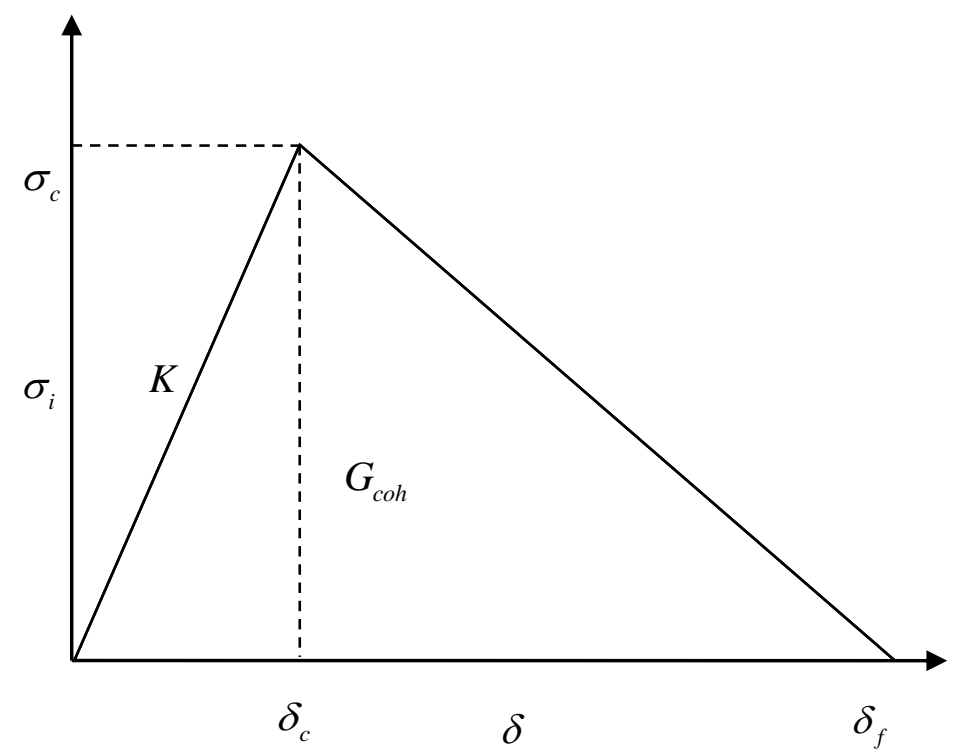

Figure 6: Bilinear cohesive zone law. 


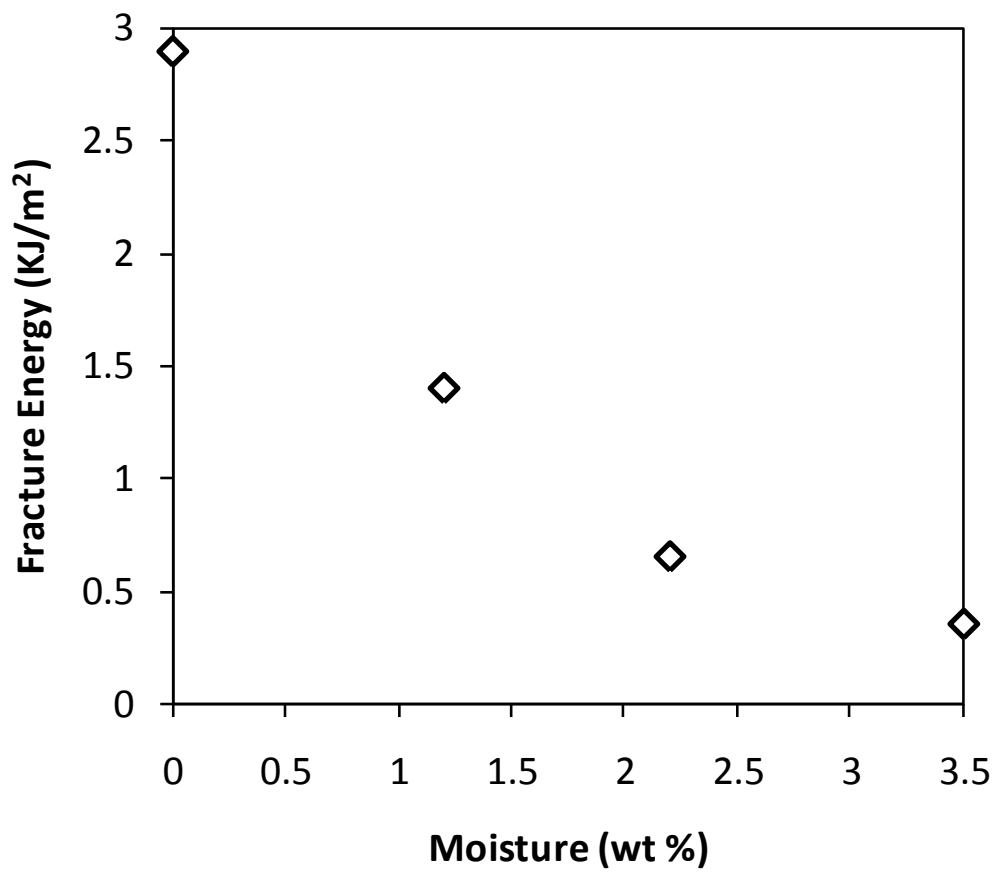

Figure 7: Moisture dependent fracture energy of the adhesive.

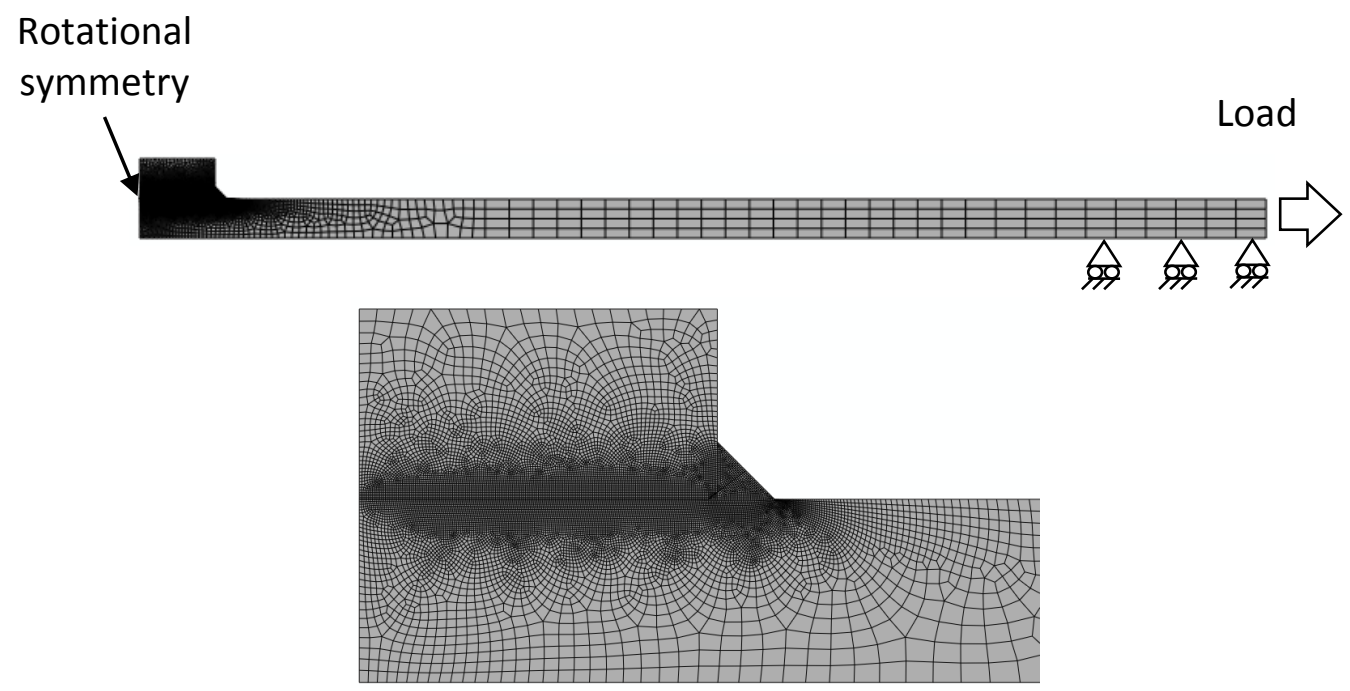

Figure 8: Mesh and boundary conditions of two dimensional single lap joint model. 


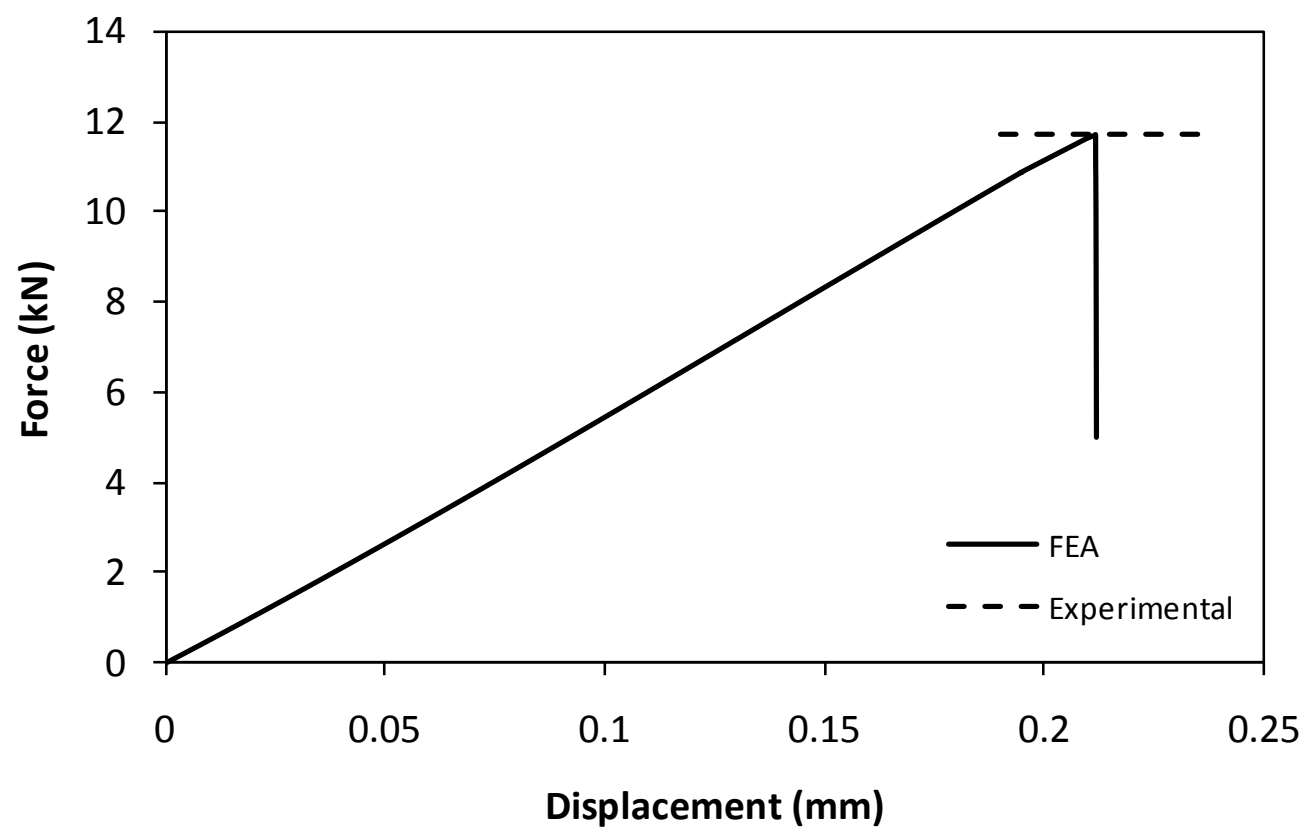

Figure 9: Force vs. displacement response of the two dimensional single lap joint.

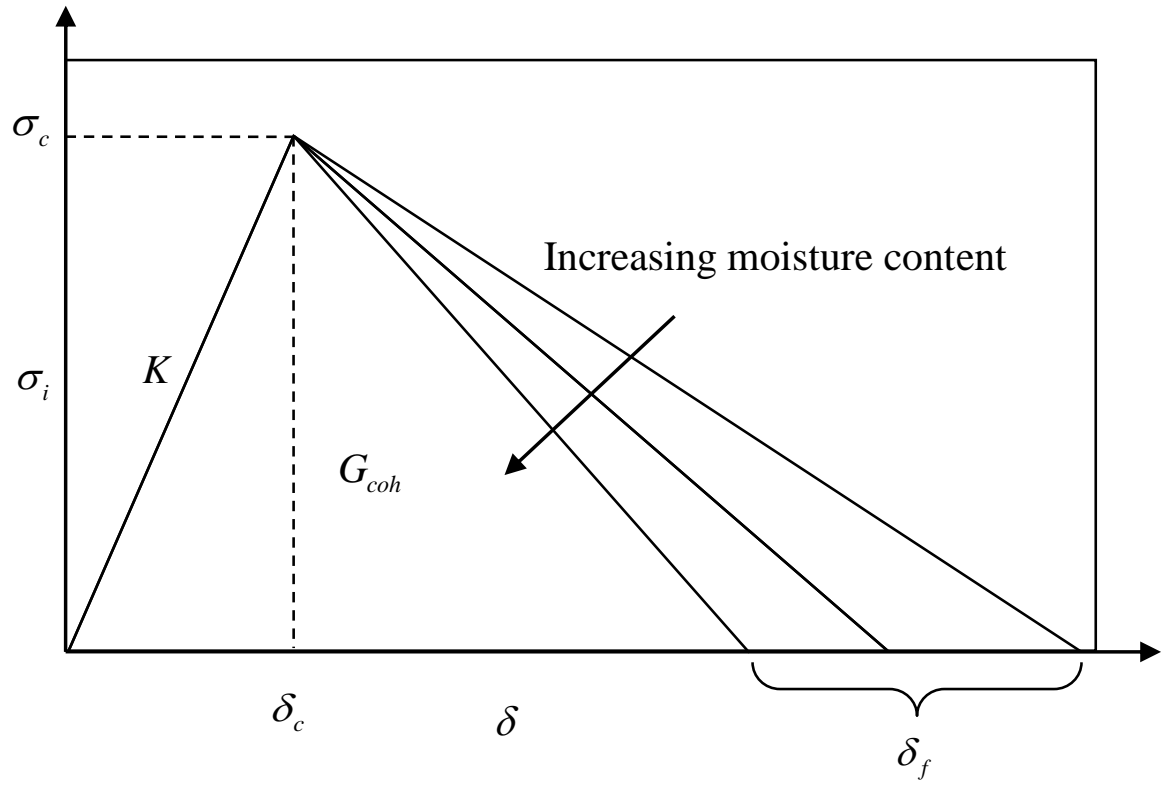

Figure 10: Change in bilinear cohesive zone law with increasing moisture concentration. 


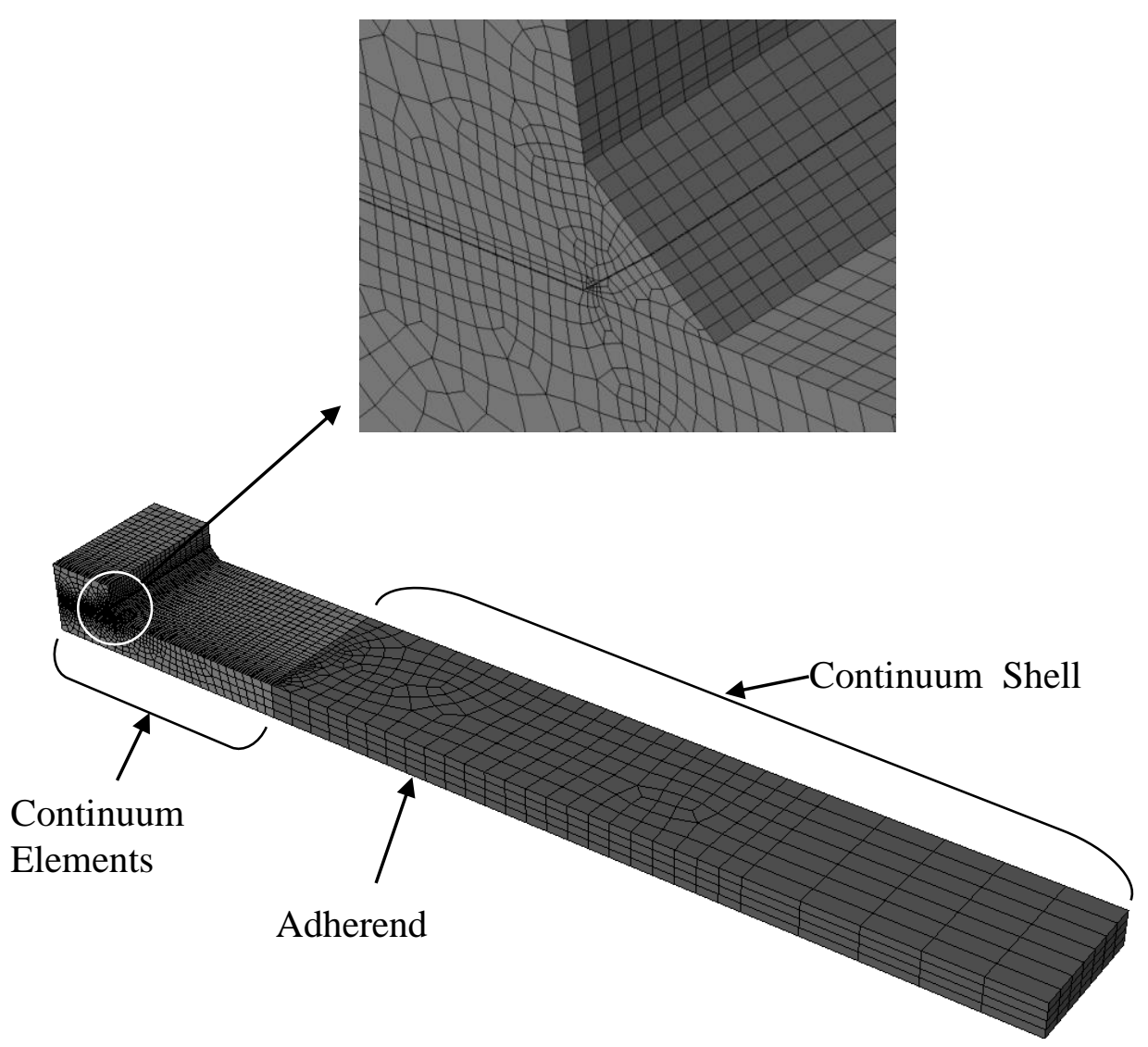

Figure 11: The 3D mesh used for CZM based analysis of single lap joints.

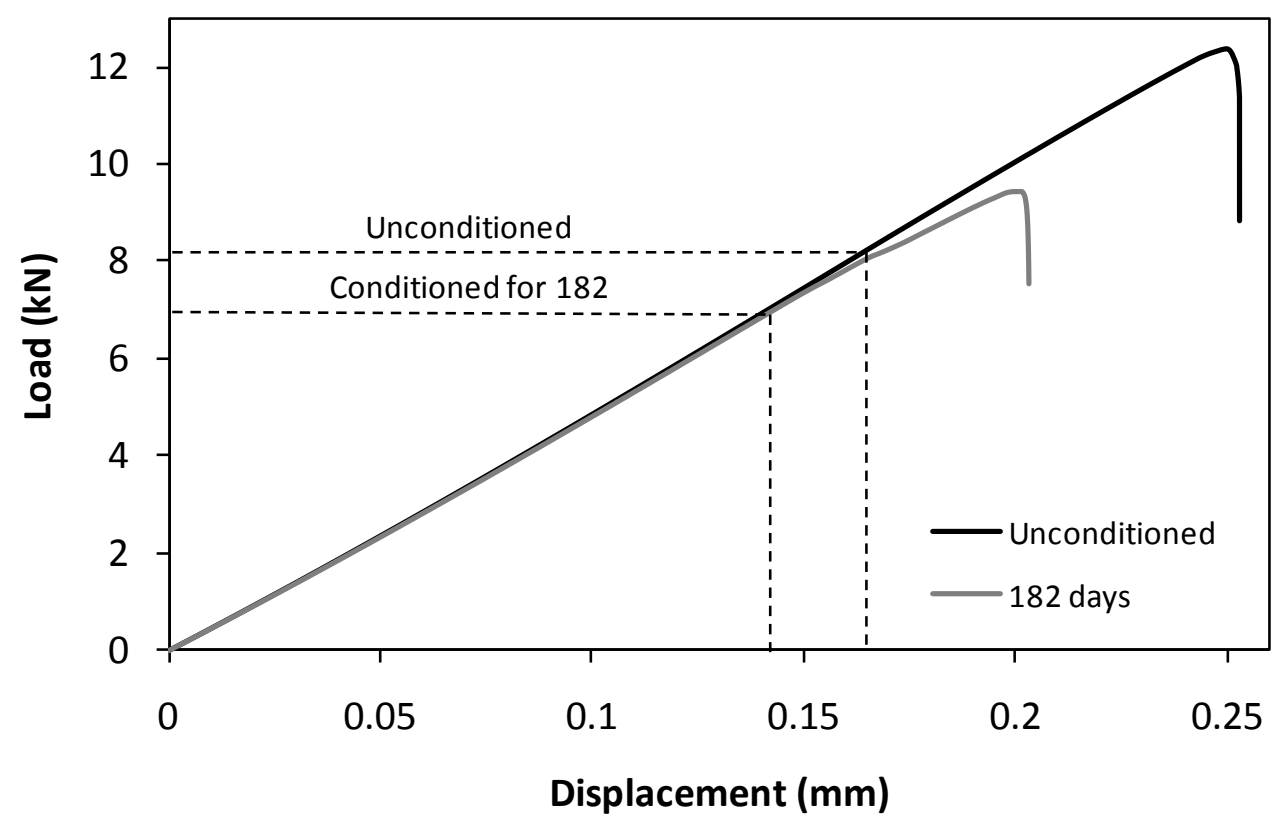

Figure 12: FEA predicted force-displacement response of Al2024 T3 unconditioned and 182 days conditioned joints. 


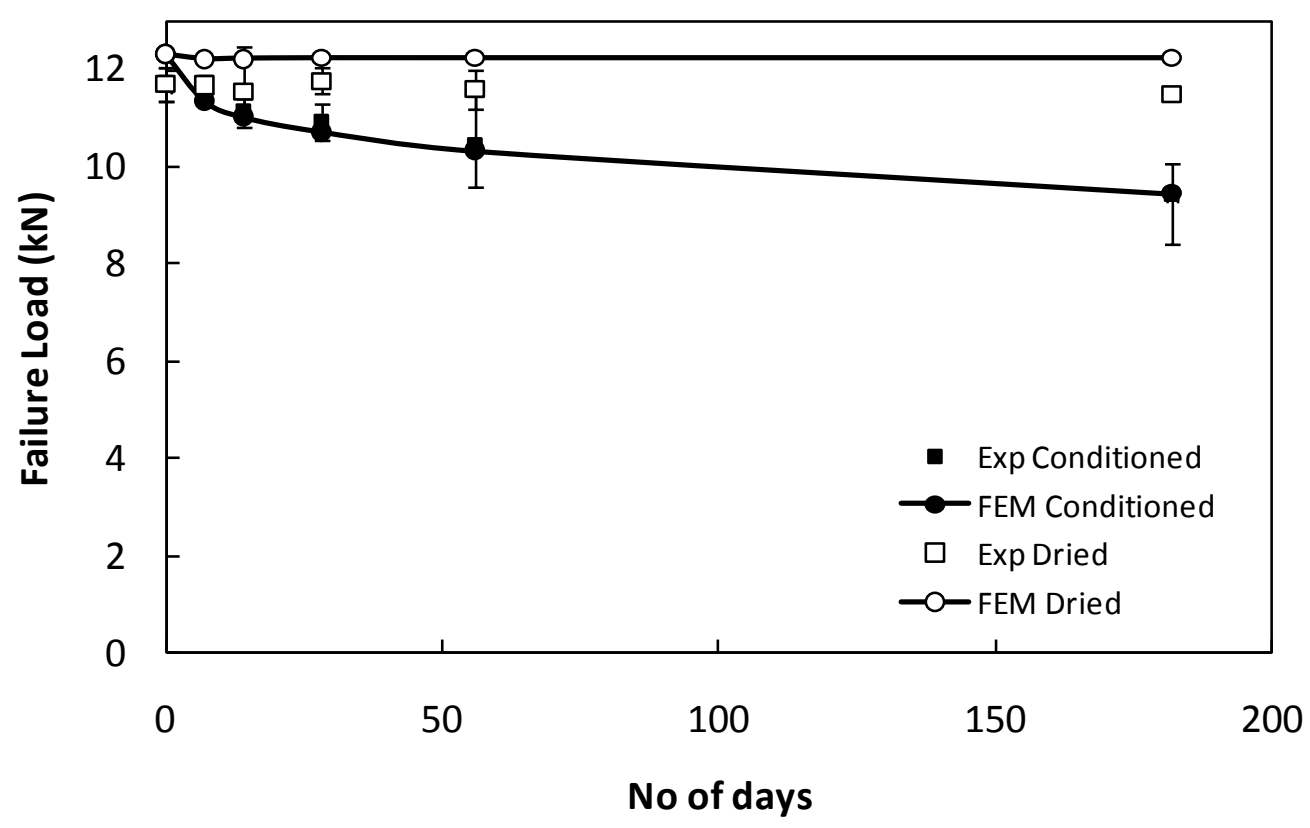

Figure 13: Predicted and experimental failure load of the Al2024 T3 joints when conditioned at $50^{\circ} \mathrm{C}$.

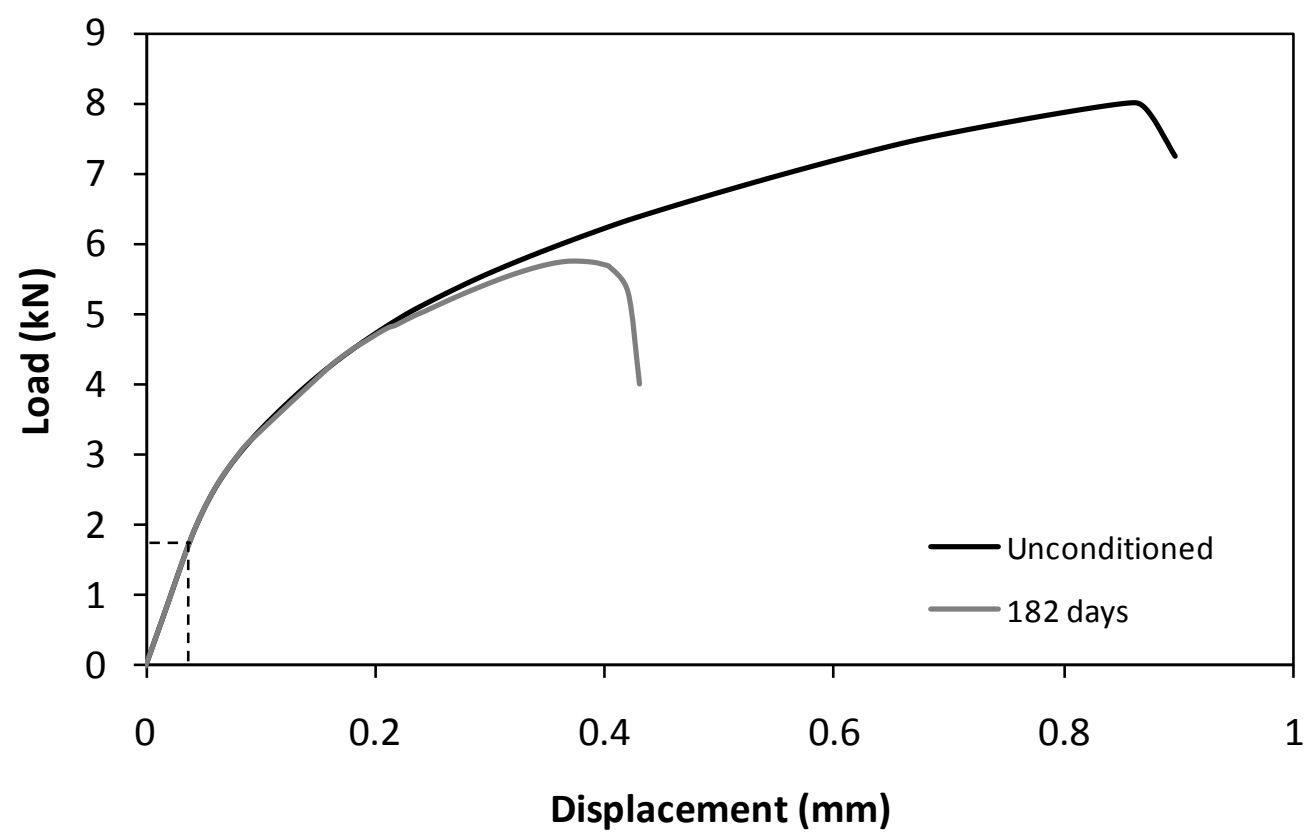

Figure 14: FEA predicted force-displacement response of Al2024 O unconditioned and 182 days conditioned joint. 
(a)

(b)

Figure 15: Plastic deformation in $\mathbf{A 1 2 0 2 4} O$ adherends after failure during tensile testing (a) experimental (b) FEM.

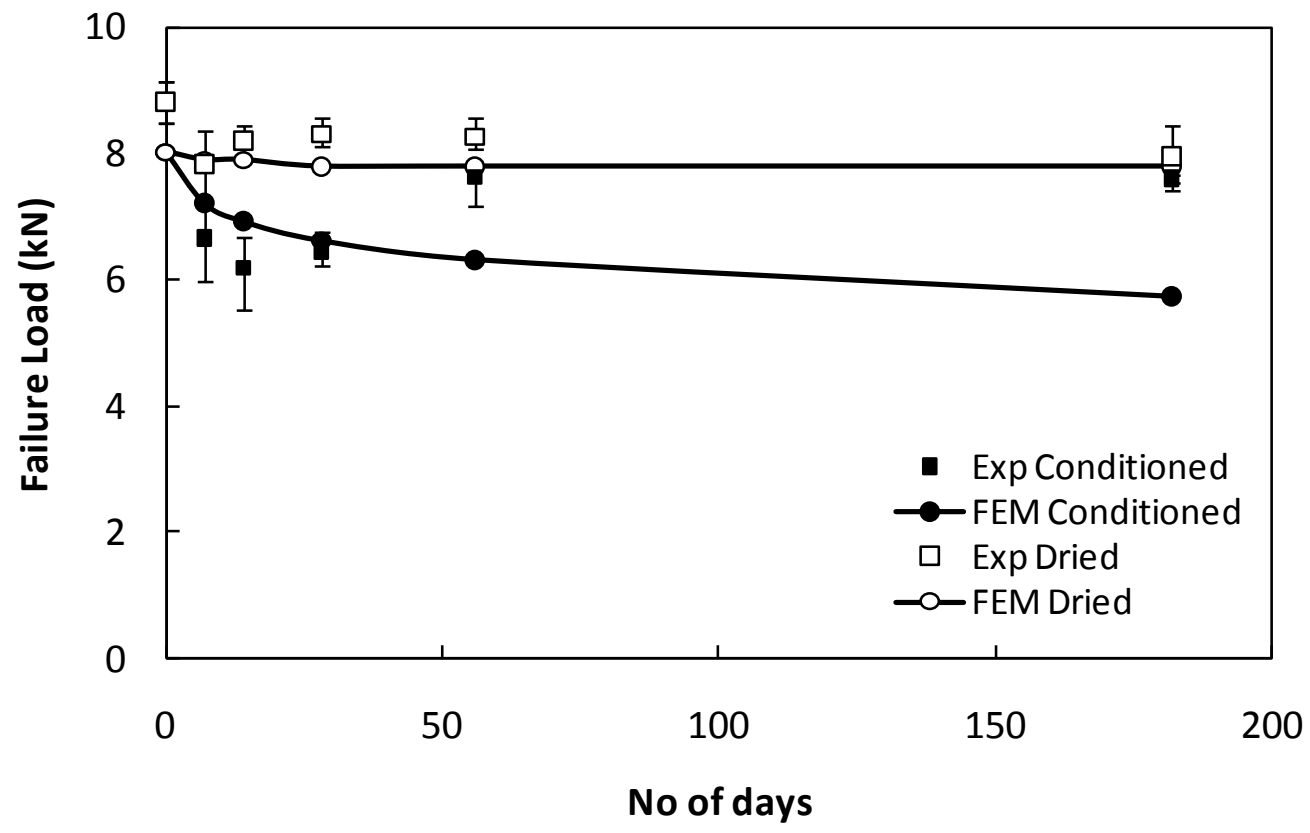

Figure 16: Predicted and experimental failure load of the Al2024 O joints when conditioned at $50^{\circ} \mathrm{C}$. 


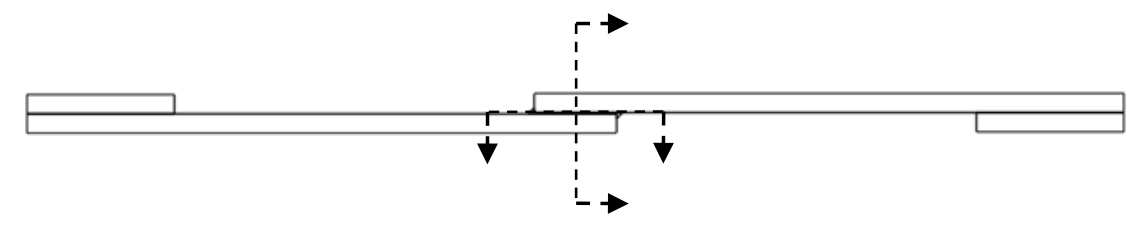

(a)

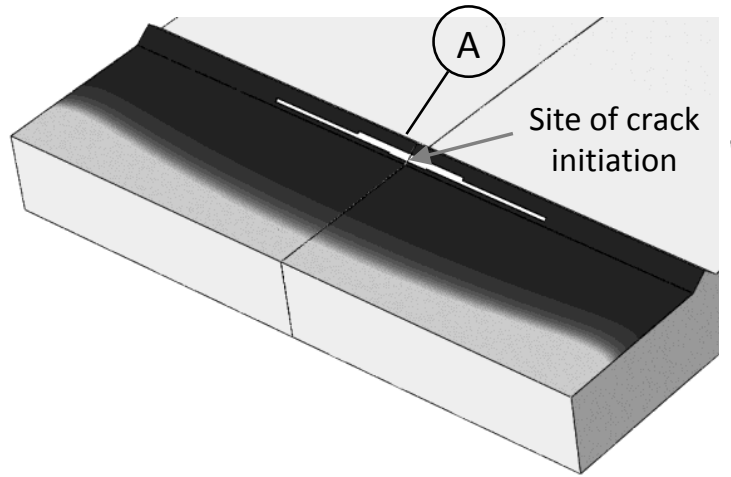

(b) $\mathrm{Load}=5.9 \mathrm{kN}$

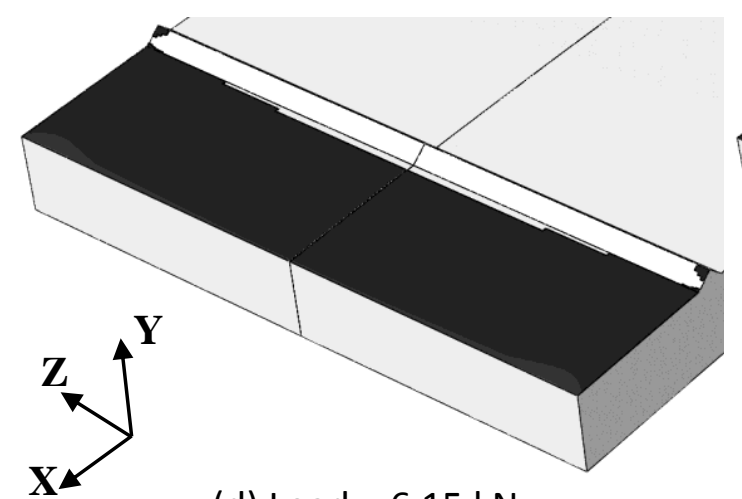

(d) Load $=6.15 \mathrm{kN}$

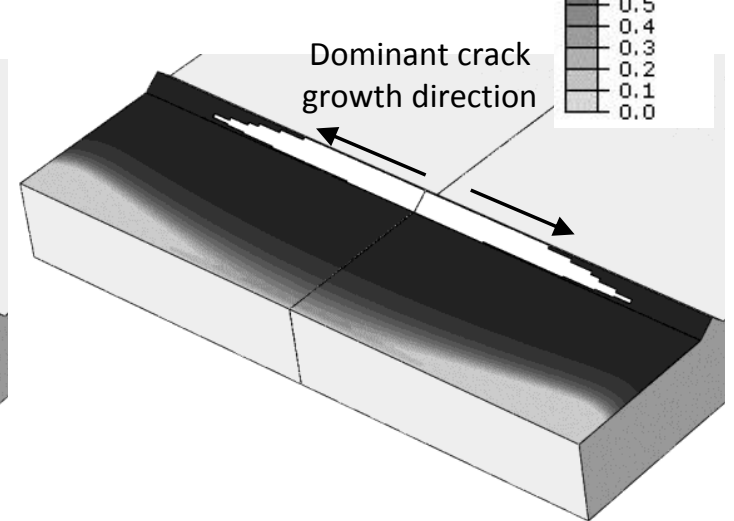

(c) $\mathrm{Load}=6.1 \mathrm{kN}$

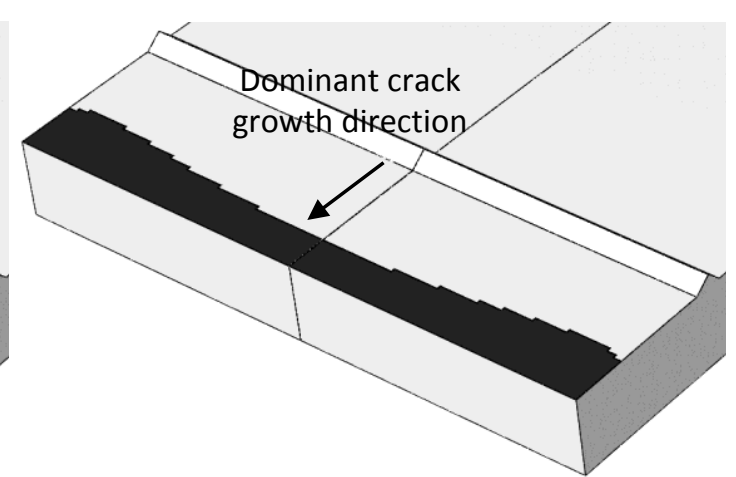

(e) $\mathrm{Load}=5.8 \mathrm{kN}$

Figure 17: Damage and crack propagation in unconditioned Al2024 T3 single lap joint. 


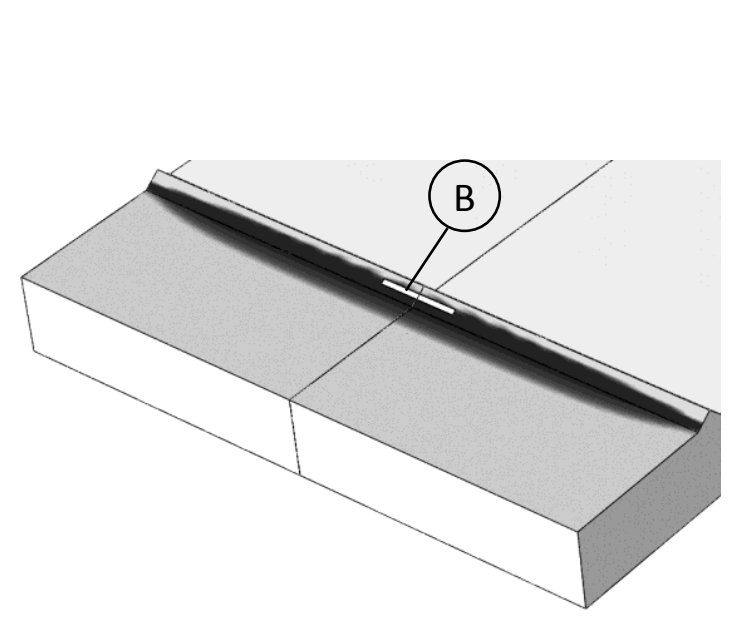

(a) Load $=3.6 \mathrm{kN}$

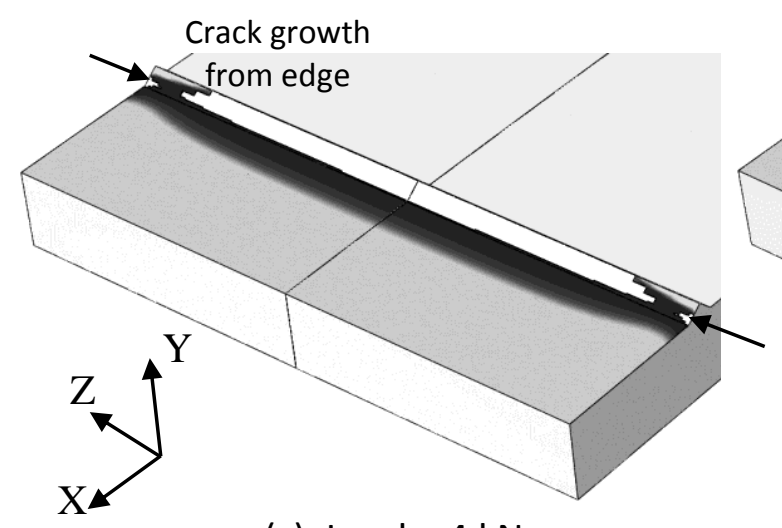

(c) Load $=4 \mathrm{kN}$

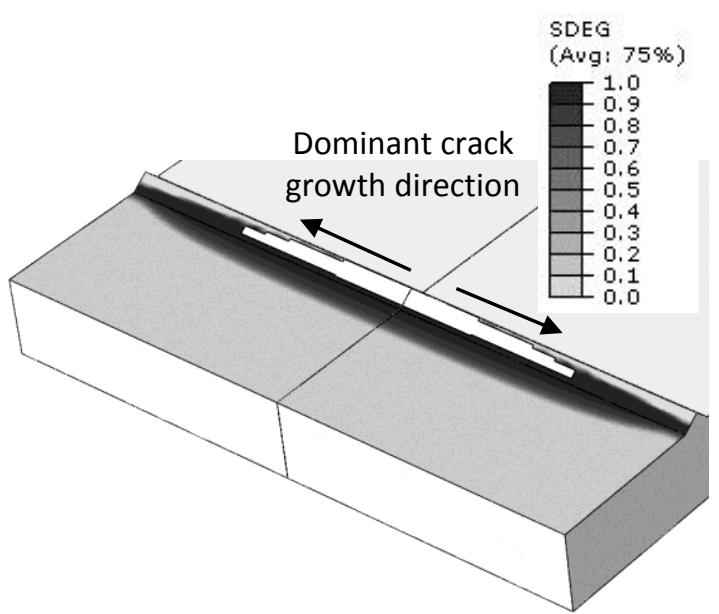

(b) Load $=3.8 \mathrm{kN}$

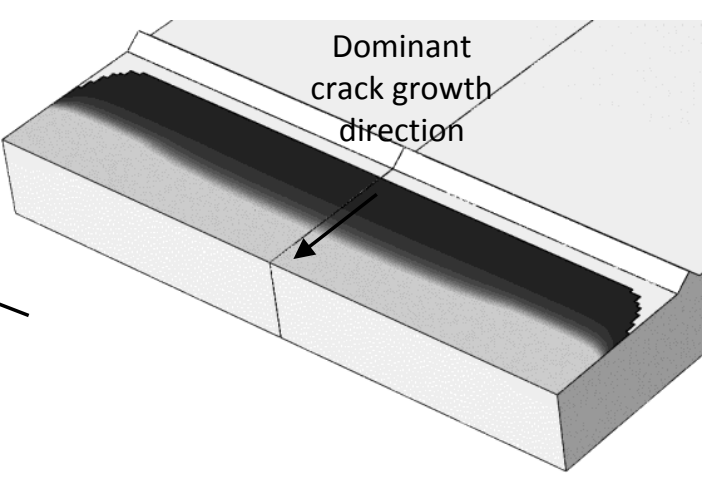

(d) Load $=4.6 \mathrm{kN}$

Figure 18: Damage and crack propagation Al2024 T3 joints, conditioned at $50^{\circ} \mathrm{C}$ for 182 days. 


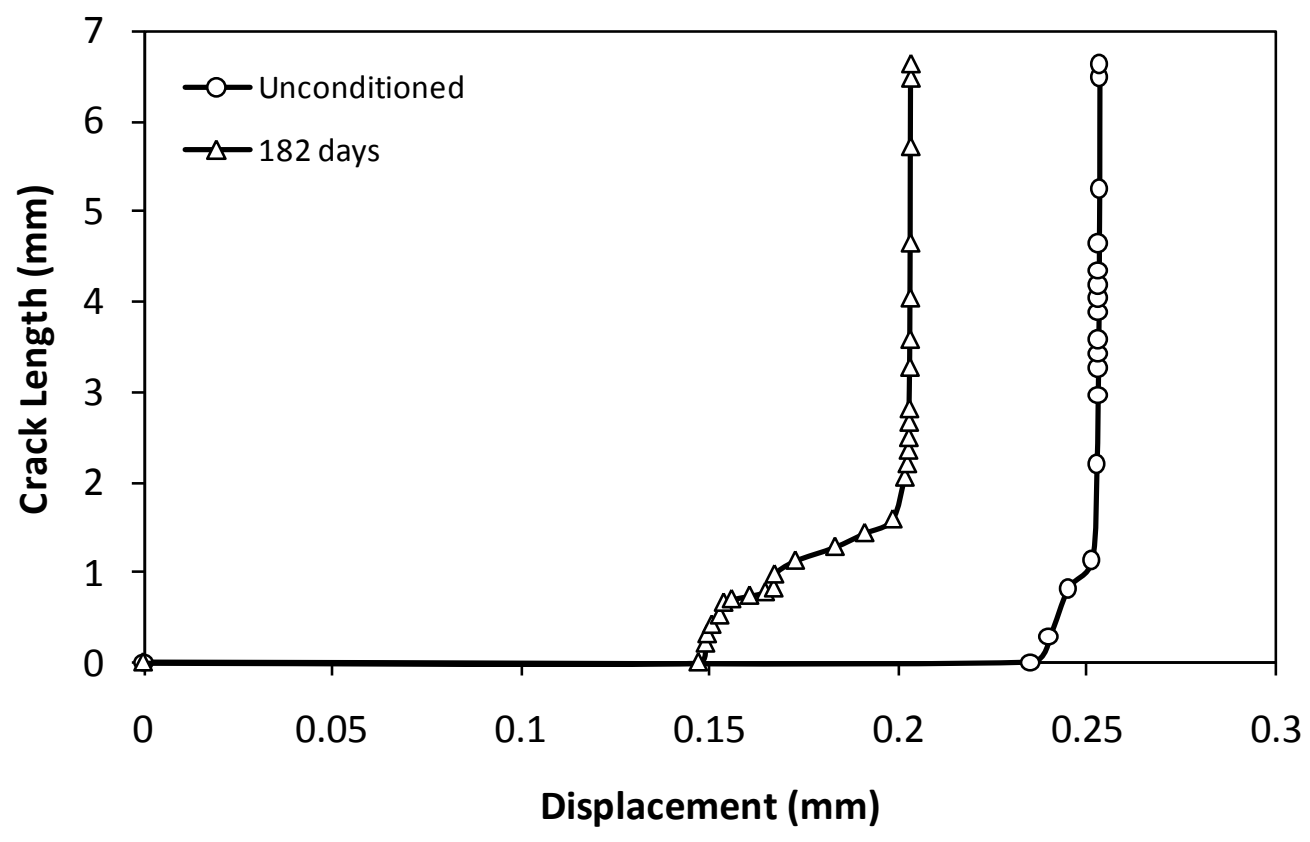

Figure 19: Crack length of $\mathrm{Al} 2024 \mathrm{T3}$ joints, conditioned at $50^{\circ} \mathrm{C}$, as a function of displacement. 


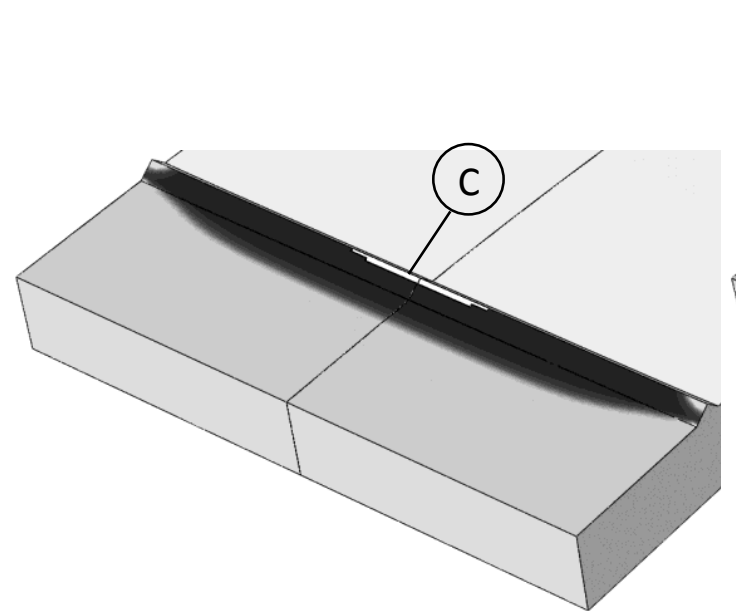

(a) Load $=3.2 \mathrm{kN}$

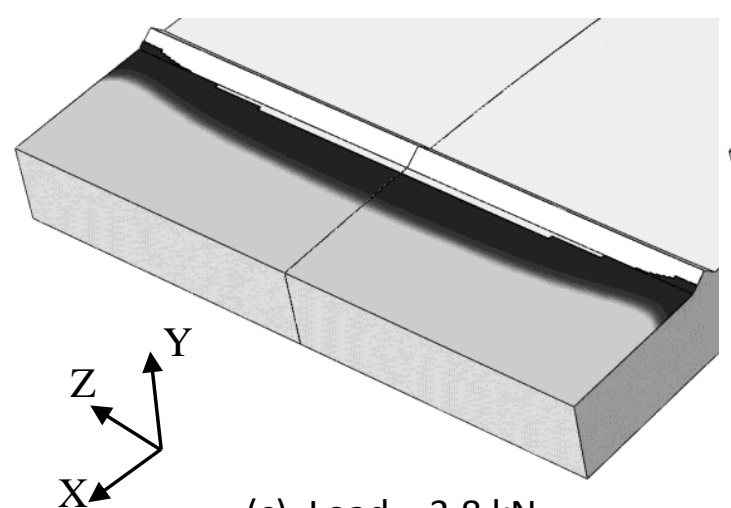

(c) Load $=3.8 \mathrm{kN}$

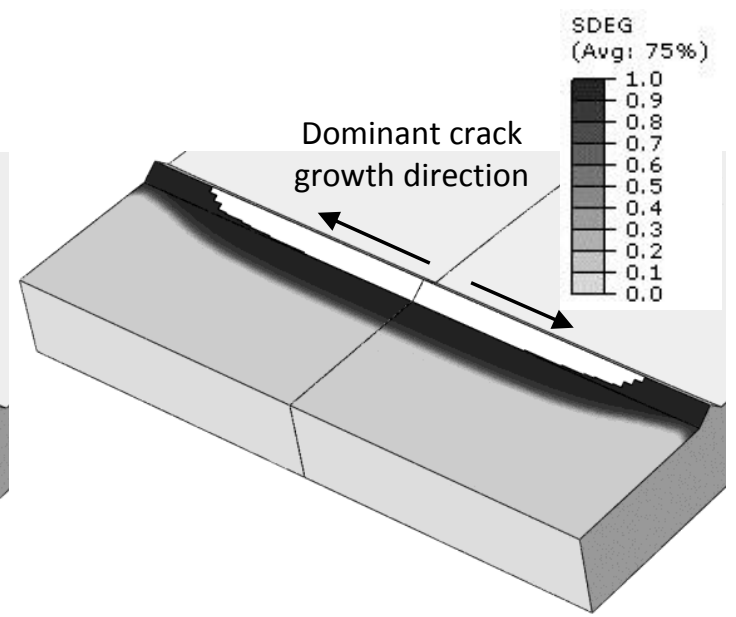

(b) Load $=3.6 \mathrm{kN}$

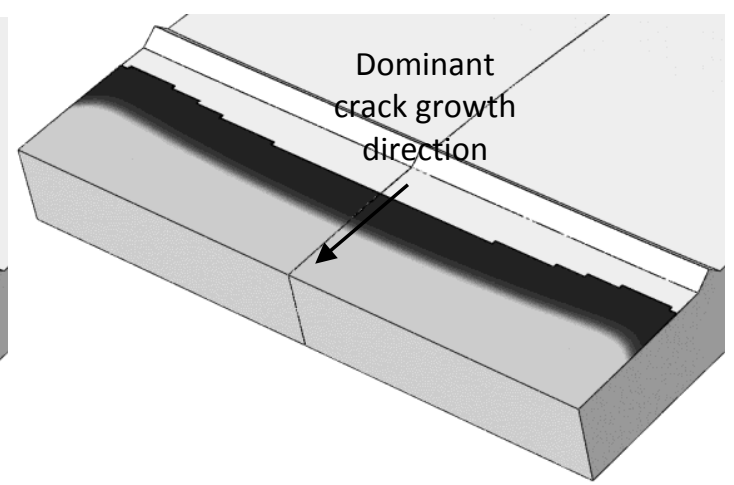

(d) Load $=4 \mathrm{kN}$

Figure 20: Damage and crack propagation in unconditioned Al2024 O single lap joint. 


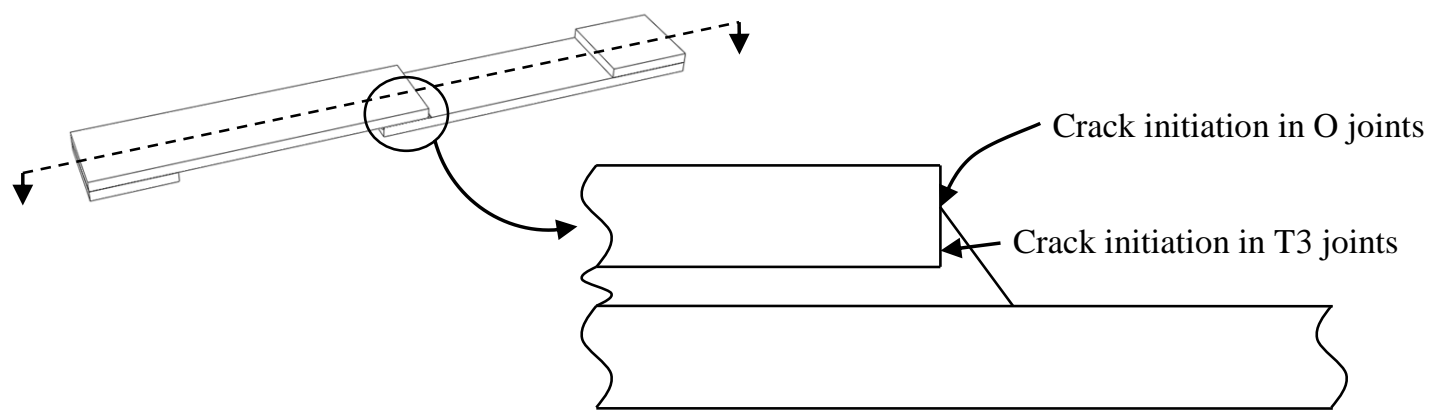

Figure 21: Site of crack initiation in unconditioned Al2024 T3 and O joints. 


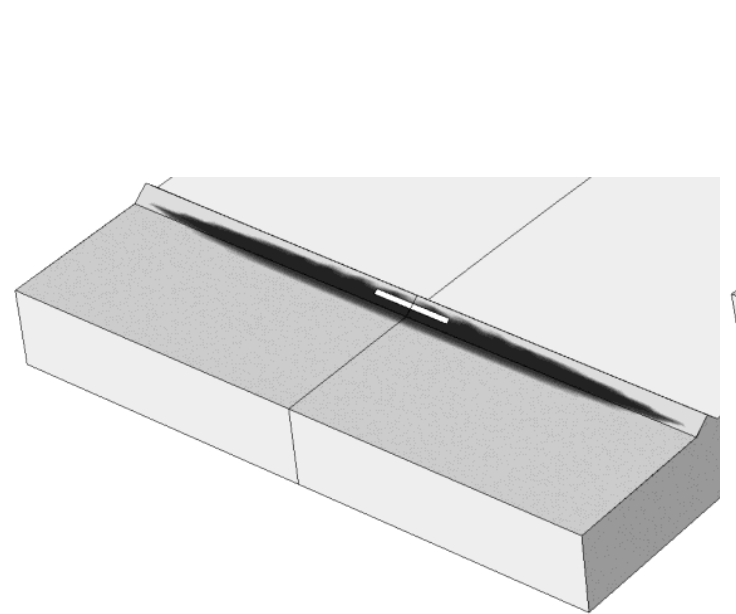

(a) Load $=2.2 \mathrm{kN}$

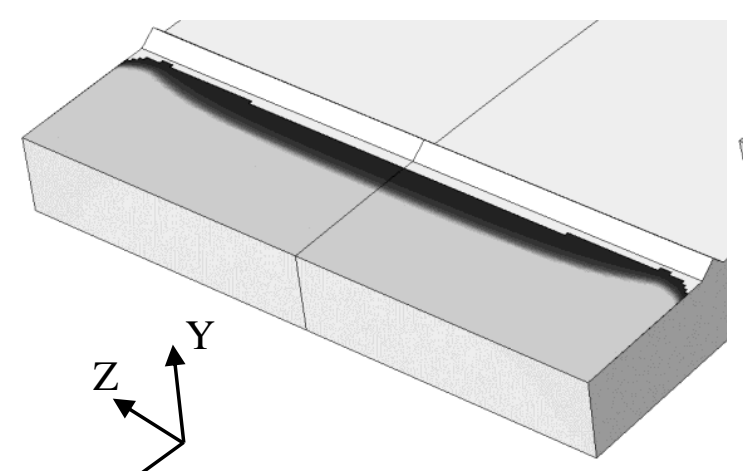

(c) $\mathrm{Load}=2.6 \mathrm{kN}$

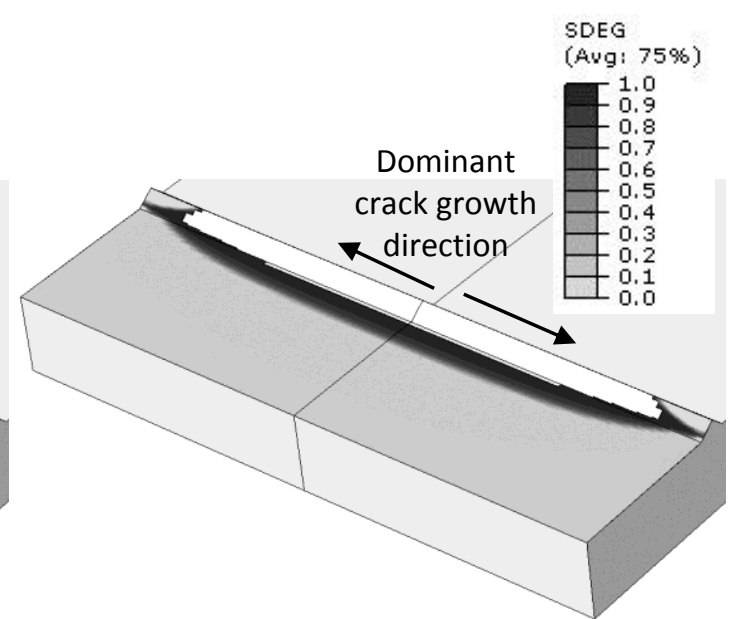

(b) Load $=2.4 \mathrm{kN}$

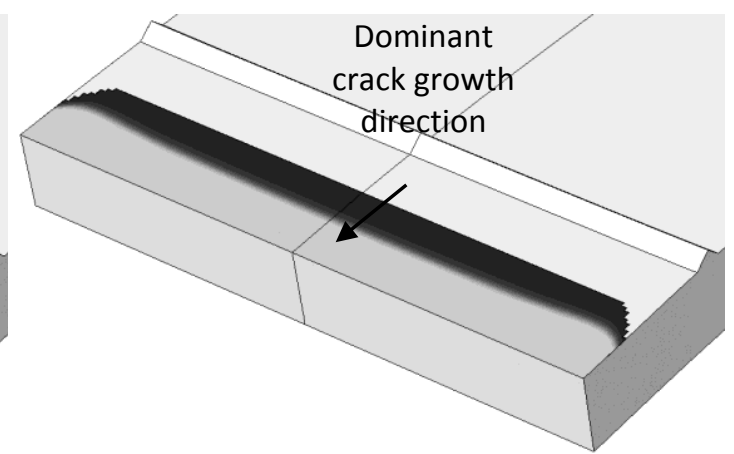

(d) Load $=2.9 \mathrm{kN}$

Figure 22: Damage and crack propagation Al2024 O single lap joint, conditioned at $50^{\circ} \mathrm{C}$ for 182 days. 


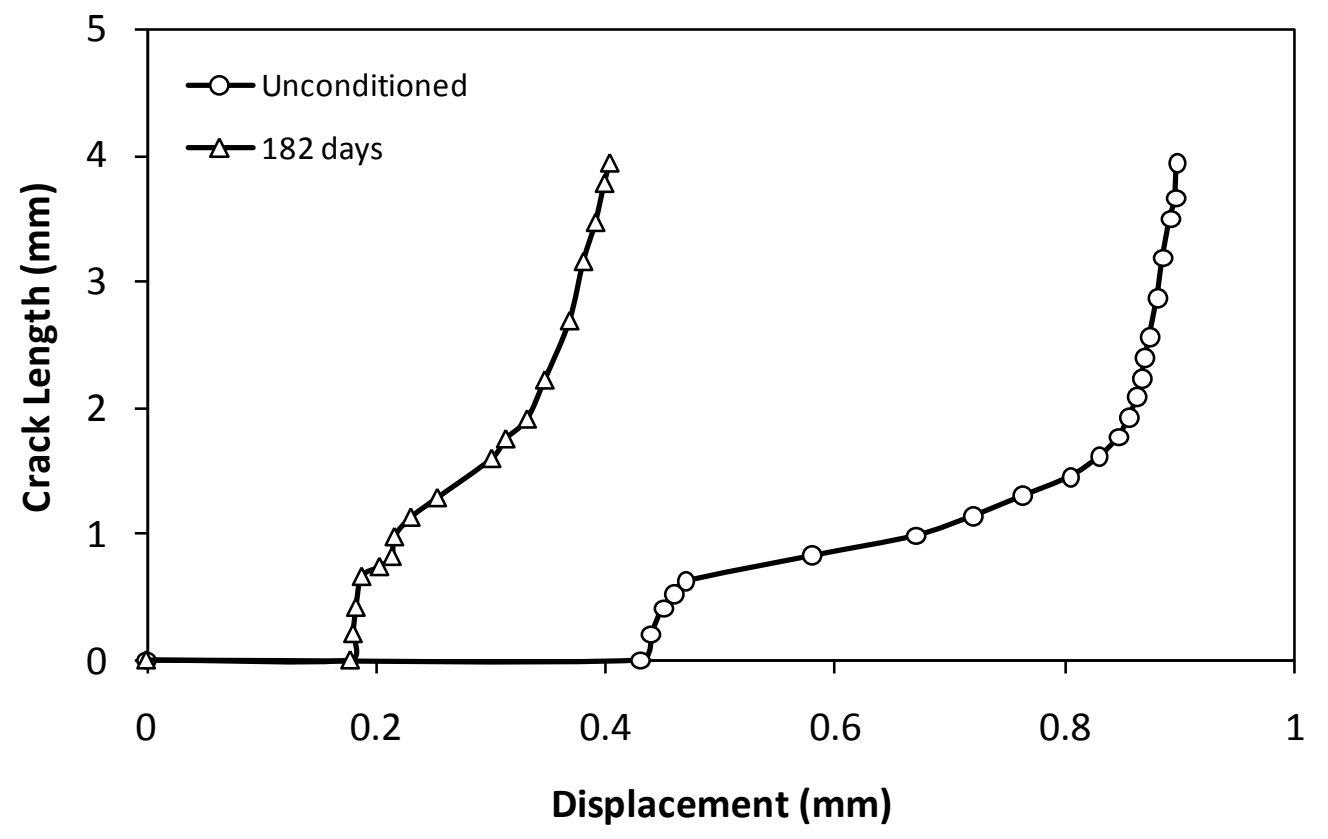

Figure 23: Crack length as a function of displacement in Al2024 O joints conditioned at $50^{\circ} \mathrm{C}$. 
Table 1: Mechanical properties of aluminium alloy 2024 T3 [37] and 0.

\begin{tabular}{lcc}
\hline \multicolumn{1}{c}{ Mechanical Property } & Value \\
\hline Elastic modulus (GPa) & 73 \\
Poisson's ratio & & 0.33 \\
Yield Strength (MPa) & T3 & 345 \\
& O & 75.8 \\
Coefficient of thermal expansion [38] & $23.2 \times 10^{-6} \mathrm{~K}^{-1}$ \\
\hline
\end{tabular}

Table 2: The cohesive zone model parameters for dry single lap joint.

\begin{tabular}{ccc}
\hline $\begin{array}{c}\text { Tripping traction } \\
\sigma_{c}(\mathrm{MPa})\end{array}$ & $\begin{array}{c}\text { Stiffness } \\
K\left(\mathrm{~N} / \mathrm{mm}^{3}\right)\end{array}$ & $\begin{array}{c}\text { Cohesive energy } \\
G_{c o h}\left(\mathbf{k J} / \mathbf{m m}^{2}\right)\end{array}$ \\
\hline 39 & $1 \times 10^{5}$ & 2.9 \\
\hline
\end{tabular}

